Boletín de la Sociedad Geológica Mexicana

Volumen Conmemorativo del Centenario

Grandes Fronteras Tectónicas de México

Toмo LVII, NÚM. 1, 2005, P. 83-109

\title{
La falla de Caltepec: raíces expuestas de una frontera tectónica de larga vida entre dos terrenos continentales del sur de México
}

\author{
Mariano Elías-Herrera1,", Fernando Ortega-Gutiérrez ${ }^{1}$, José Luis Sánchez-Zavala1, Consuelo \\ Macías-Romo', Amabel Ortega-Rivera ${ }^{2}$, Alexander Iriondo ${ }^{3}$ \\ ${ }^{1}$ Instituto de Geología, Universidad Nacional Autónoma de México, \\ Ciudad Universitaria, Deleg. Coyoacán, 04510, México, D.F. \\ ${ }^{2}$ Estación Regional del Noroeste, Instituto de Geología, Universidad Nacional Autónoma de México, \\ L.D. Colosio y Madrid S/N, Campus Unison, Apartado Postal 1039, 83000 Hermosillo, México \\ ${ }^{3}$ Centro de Geociencias, Universidad Nacional Autónoma de México, \\ Campus Juriquilla, Querétaro, Qro., 76230, México \\ *elias@servidor.unam.mx
}

\begin{abstract}
Resumen
En este trabajo se discuten las características geológicas de la falla de Caltepec, una zona de cizalla de larga vida con dirección norte-sur y mecanismo transpresional derecho que separa a los terrenos Zapoteco al oriente y Mixteco al poniente al nivel de sus basamentos metamórficos (complejos Oaxaqueño y Acatlán). Los excelentes afloramientos (área de Caltepec) que exponen completamente el contacto en una anchura variable entre 2 y 6 km revelan una actividad tectonomagmática y metamórfica del Pérmico temprano relacionada con la yuxtaposición de los complejos cristalinos durante la consolidación de Pangea, y registran también períodos múltiples de reactivación mesozoicos, cenozoicos y probablemente hasta recientes. Con base en la cartografía geológico-estructural detallada y estudios petrográficos, geocronológicos e isotópicos, se determinó un rango de edad de 275.6-270.4 Ma para el evento de cizalla dúctil en la zona de falla mediante fechamientos $\mathrm{U}-\mathrm{Pb}$ en circones de un leucosoma anatéctico y granito sintectónico (granito Cozahuico). Se establece también una estructura en semiflor con su cima en posición casi vertical y su base cabalgada hacia el poniente con desplazamientos indeterminados. Las relaciones iniciales de ${ }^{87} \mathrm{Sr}{ }^{86} \mathrm{Sr}(0.70435-0.70686)$ y edades modelo Sm-Nd $\left(\mathrm{T}_{\mathrm{DM}}\right)(1.0-1.6 \mathrm{Ga})$ para el granito Cozahuico y el leucosoma indican un origen por mezcla magmática entre corteza local proterozoica y una componente de manto empobrecido. La edad leonardiana de la cobertura discordante (Formación Matzitzi) y una edad de enfriamiento ${ }^{40} \mathrm{Ar} /{ }^{39} \mathrm{Ar}$ (moscovita) de 268.6 Ma para un esquisto de mica milonítico en la base de la cabalgadura, implica tasas altas de enfriamiento $\left(\sim 180^{\circ} \mathrm{C} / \mathrm{Ma}\right)$ y levantamiento durante el Pérmico. Por otro lado, el registro sedimentológico adyacente indica reactivación tectónica intensa durante el Cretácico Inferior, Paleógeno y Neógeno a lo largo de la falla de Caltepec, alternando con periodos de estabilidad tectónica relativa durante el Triásico, Jurásico y Cretácico medio. La orientación paralela de las fallas de Caltepec y Oaxaca, distante decenas de kilómetros al oriente de la primera, se interpreta como partes de un sistema estructural sincrónico y dinámicamente acoplado que ha estado liberando alternadamente los esfuerzos tectónicos asociados con la ruptura de Pangea y la evolución del margen del Pacífico del sur de México desde el Jurásico hasta el Holoceno en esta región.
\end{abstract}

Palabras clave: Falla mayor, límite de terrenos, Complejo Acatlán, Complejo Oaxaqueño, México meridional. 
Abstract

This work presents the main geologic characteristics of the long-lived Caltepec fault zone, a N-S trending, righttranspressional shear zone that separates the Zapoteco terrane on the east from the Mixteco terrane on the west at their basement level (Oaxaqueño and Acatlan complexes). The high quality of the outcrops (Caltepec area), entirely exposing a 2-6 km wide tectonic contact, reveals protracted and polyphase tectonic activity on the fault from at least early Permian time to the present. Based on detailed geological mapping, petrography, geochronology, and isotopic studies, it is shown that the tectonothermal event in the Caltepec fault zone is related to the oblique collision of the metamorphic complexes during the amalgamation of Pangea. An anatectic leucosome and the resulting syntectonic granite (Cozahuico granite) in the fault zone yielded U-Pb zircon ages of 275.6 and $270.4 \mathrm{Ma}$. It is also established a half-flower structure for the fault zone, with the top lying almost vertical and its base thrusted westward with unknown displacements. The initial ${ }^{87} \mathrm{Sr} /{ }^{86} \mathrm{Sr}$ ratios (0.70435-0.70686) and Sm-Nd model ages $\left(T_{D M}\right)$ (1.0-1.6 Ga) for the Cozahuico granite and leucosome indicate a magmatic mixture that originated from melted Proterozoic crust and a component of depleted mantle. The leonardian age for the cover (Matzitzi Fm.) and $a^{40} \mathrm{Ar}{ }^{\beta 9} \mathrm{Ar}$ cooling age (muscovite) of $268.6 \mathrm{Ma}$ for a mylonitic mica schist at the sole of the thrust, implies high ratios of cooling $\left(\sim 180^{\circ} \mathrm{C} / \mathrm{Ma}\right)$ and uplift during the Permian. On the other hand, the adjacent sedimentological record indicates intense tectonic reactivation during Early Cretaceous, Paleogene, and Neogene times along the long-lived Caltepec fault zone, alternating with periods of relative tectonic quiescence during Triassic, Jurassic, and mid Cretaceous times. The trend of the Caltepec fault zone, parallel to the Oaxaca fault, distant only a few kilometers to the east, is interpreted as part of a synchronous and dynamically coupled tectonic system. This coupled system has liberated tectonic stresses associated with the rupture of Pangea and the evolution of the Pacific margin of southern Mexico from Jurassic to Holocene times.

Key words: Major fault, terrane boundary, Acatlán Complex, Oaxacan Complex, southern Mexico.

\section{Introducción}

El sur de México es sin duda una de las regiones del país que presenta más problemas geológicos sin resolver, ya que su evolución tectónica dista mucho de ser plenamente comprendida en términos de una visión moderna de tectónica de placas. Las rocas de esta región, cuya ubicación en modelos de reconstrucción paleogeográfica ha sido incierta desde hace casi cuatro décadas (e.g., Bullard et al., 1965), están agrupadas en los terrenos Zapoteco, Mixteco, Cuicateco, Chatino y Guerrero meridional (Figura 1). En conjunto las rocas registran una historia geológica de $>1.0 \mathrm{Ga}$ ligada esencialmente a los sistemas orogénicos Grenvilliano, Apalachiano-Alleghaniano y Cordillerano de América del Norte, así como a eventos geológicos relacionados con el rompimiento y dispersión de Pangea y con la evolución tectónica cenozoica de la cuenca del Pacífico que modificaron sustancialmente escenarios anteriores. El sur de México es, por lo tanto, una región en donde los fenómenos a nivel cortical de deformación, metamorfismo y magmatismo y reactivación de estructuras preexistentes (e.g., Holdsworth et al., 1997, 2001a, 2001b) ocurrieron a gran escala y a diferentes profundidades durante los procesos de sepultamiento o de exhumación de la región a lo largo de su historia. Uno de los mejores ejemplos de estructuras mayores con reactivaciones múltiples en esta región del país es justamente la falla de Caltepec. Esta falla es elemento fundamental en la conformación estructural del sur de México y tema central del presente trabajo. La falla de Caltepec es una zona de cizalla longeva con una historia compleja de deformación dúctil y frágil que representa el contacto tectónico entre los basamentos cristalinos Acatlán del Paleozoico y Oaxaqueño del Mesoproterozoico, y delimita a los terrenos Mixteco y Zapoteco (Figura 1).

\subsection{Antecedentes}

Desde principios del siglo pasado la relación geológica entre los complejos metamórficos de las regiones de Acatlán y Oaxaca fue motivo de especulaciones (Ordóñez, 1905, 1906). No fue sino hasta casi siete décadas después cuando De Cserna (1970) retomó este aspecto de la geología de la parte centro-meridional de México enfatizándolo y discutiéndolo como uno de los problemas principales a resolver. Sin embargo, debido a que la zona de contacto entre ambos complejos está casi en su totalidad cubierta por rocas fanerozoicas no metamórficas, y sólo aflora plenamente en una localidad poco accesible al sur de Caltepec, zona limítrofe entre los estados de Puebla y Oaxaca (Figura 2), los primeros detalles sobre la naturaleza de este contacto empezaron a conocerse hasta mediados de los años 70 del siglo pasado. El contacto entre los complejos Acatlán y Oaxaqueño fue documentado por primera vez en la barranca El Carrizal, $10 \mathrm{~km}$ al SSE del poblado de Caltepec, Puebla, por Ortega-Gutiérrez (1975) en su tesis doctoral. En este primer reporte, el contacto, que tiene un 
rumbo general N-S, fue descrito como una zona de $\sim 300$ $\mathrm{m}$ de espesor de cataclasita/milonita foliada verticalmente, y una cuña angosta de conglomerado no deformado, sólo basculado, con fragmentos de gneis, esquisto y caliza fosilífera cretácica, confinado por fallas normales verticales justamente en el borde poniente de la zona cataclástica/ milonítica. El contacto fue considerado como un límite tectónico importante entre bloques corticales con al menos dos etapas de movimiento (Ortega-Gutiérrez, 1975). La primera etapa, con una edad precretácica indefinida y un sentido de desplazamiento incierto, se relacionó con la zona de cataclasita/milonita y una retrogresión intensa de las rocas granulíticas del Complejo Oaxaqueño. En esta etapa se infirió una componente fuerte de acortamiento horizontal pero con desplazamientos laterales insignificantes debido a la presencia del mismo tipo de cuerpos graníticos intrusivos en ambos bloques de la falla (Ortega-Gutiérrez, 1975). La segunda etapa fue claramente deducida por la cuña tectónica de conglomerado y se caracterizó esencialmente por movimientos diferenciales poscretácicos a lo largo de fallas normales. Ortega-Gutiérrez (1978) interpretó el contacto entre los complejos Acatlán y Oaxaqueño como una gran falla normal con épocas diversas de actividad y rotación tectónica.

El límite tectónico fue posteriormente descrito como una zona de cizalla dúctil vertical con rumbo N-S en el área de Los Reyes Metzontla, $5 \mathrm{~km}$ al norte de Caltepec, y su continuidad hacia el sur en el subsuelo se infirió por $200 \mathrm{~km}$ hasta la región de Juchatengo (Figura 1), porción meridional del estado de Oaxaca (Ortega-Gutiérrez, 1981). Esta frontera tectónica se interpretó entonces como una sutura paleozoica entre paleocontinentes colisionados (Ortega-Gutiérrez, 1981). Previamente, Hernández-Estevez (1980) había considerado al Complejo Acatlán como el único basamento metamórfico y cubierto discordantemente por la Formación Matzitzi del Paleozoico tardío en Los Reyes Metzontla. En esta área, sin embargo, la Formación Matzitzi no sólo cubre a esquistos del Complejo Acatlán sino también a gneises del Complejo Oaxqueño, lo cual es una relación estratigráfica clave porque implica que la yuxtaposición tectónica de los dos complejos cristalinos ocurrió antes del depósito de las capas Matzitzi. La presencia de la Formación Matzitzi encima de ambos complejos en el área ya ha sido previamente documentada por otros autores (e.g., Hernández-Lascares, 2000; GarcíaDuarte, 1999).

Como parte de la celebración del 80 aniversario de la fundación de la Sociedad Geológica Mexicana, en 1984 se editaron los trabajos relacionados con el Simposio de Tectónica de la Mixteca. Un tema importante en este simposio fue el límite tectónico entre los terrrenos Mixteco y Oaxaca (Zapoteco) sobre el que se publicaron varios artículos (Ramírez-Espinosa, 1984; González-Hervert et al., 1984; Torres-Torres et al., 1984) con interpretaciones

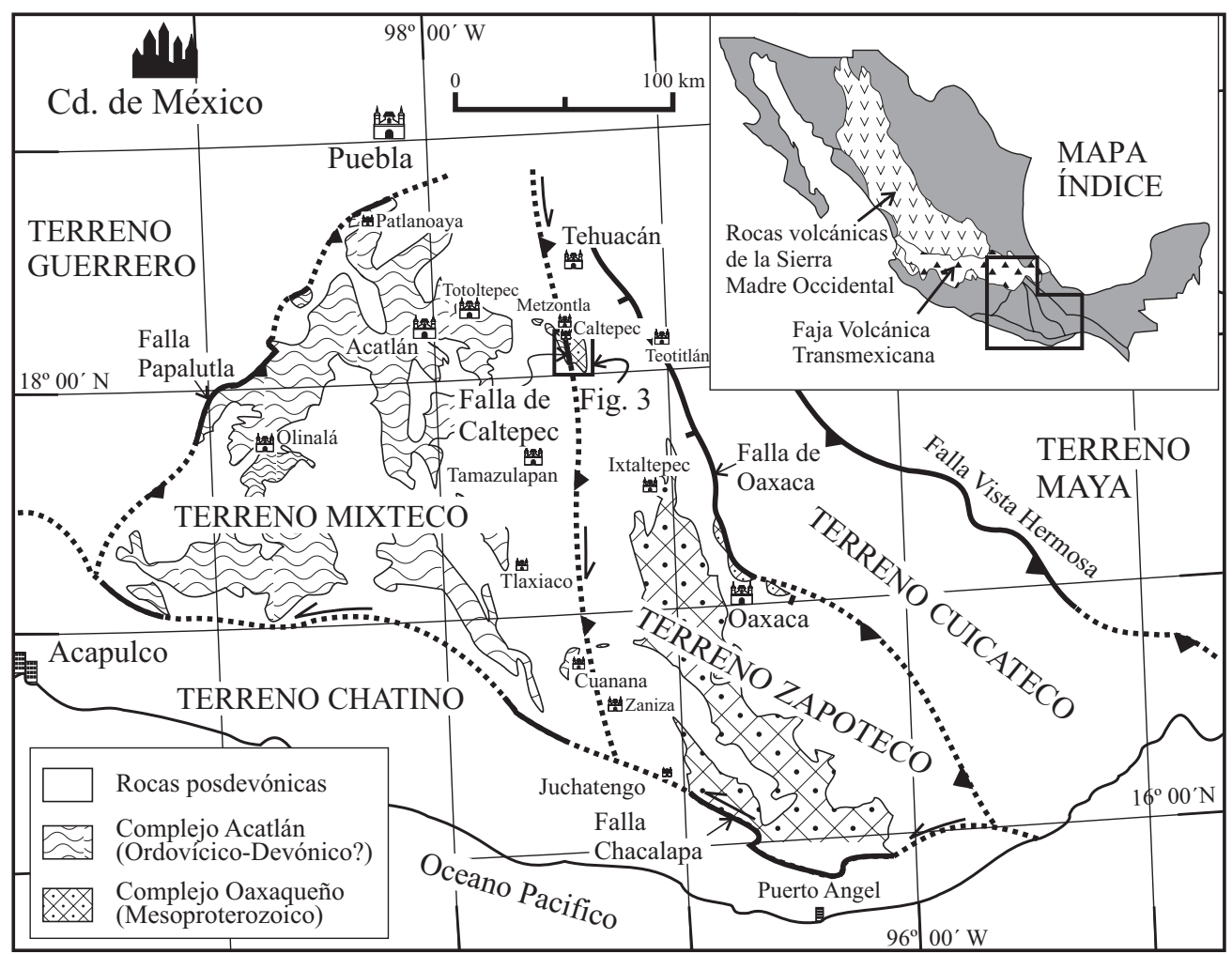

Figura 1. Mapa de la región sur de México donde se muestra el contexto tectónico de la falla de Caltepec. Los límites y nomenclatura de terrenos son de acuerdo a Sedlock et al. (1993). 


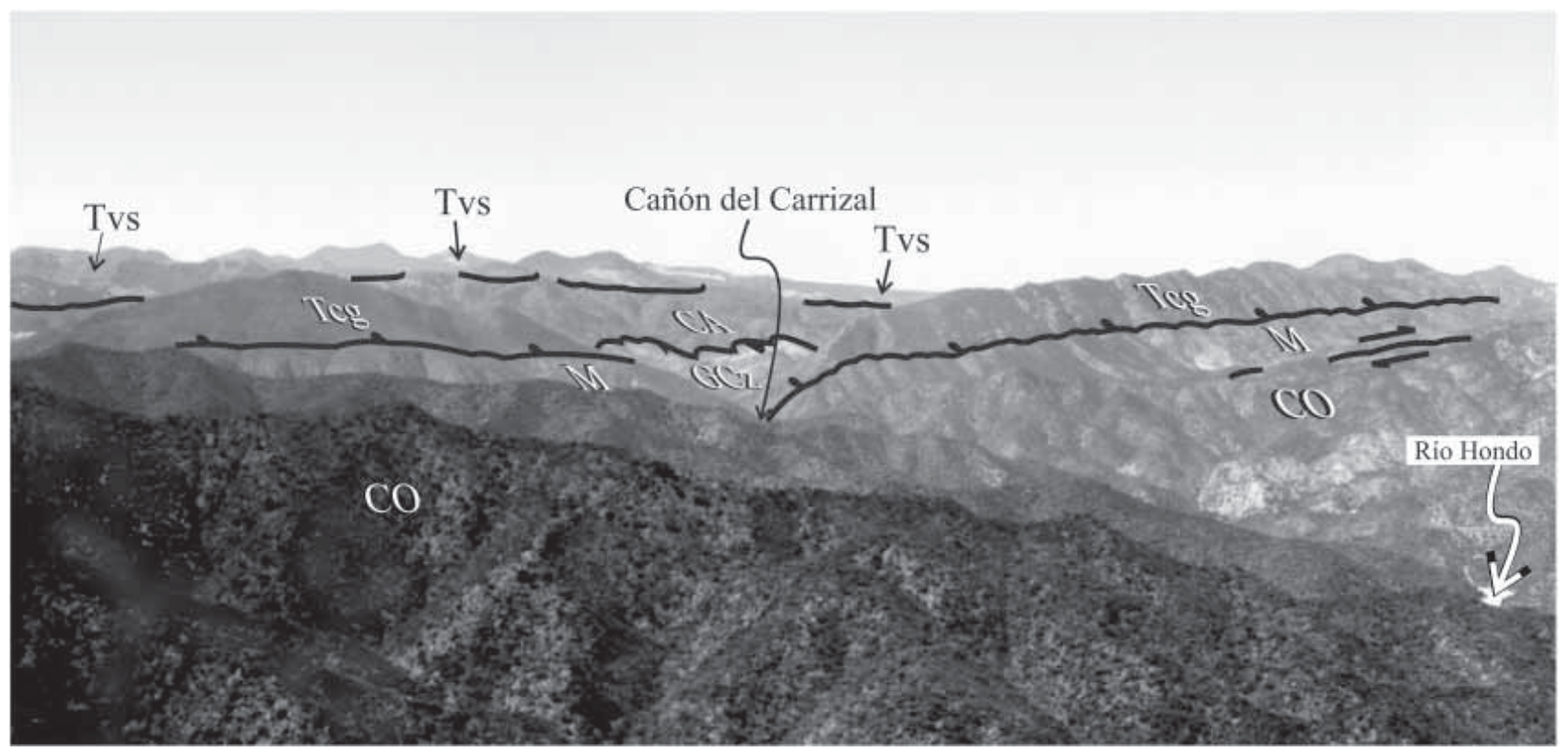

Figura 2. Vista panorámica viendo hacia el WNW de la zona de falla de Caltepec, sector limítrofe entre los estados de Puebla y Oaxaca, en la que se señalan las distintas unidades litológicas que conforman el relieve geomorfológico. CO, Complejo Oxaqueño; CA, Complejo Acatlán; M, milonita (gneises granulíticos completamente milonitizados); GCz, granito Cozahuico (plutón sintectónico sellador); Tcg, conglomerado paleogénico con clastos de caliza cretácica fosilífera, gneis y esquisto; Tvs, rocas volcanosedimentarias oligocénicas.

alternativas. Ramírez-Espinosa (1984) consideró que los terrenos Mixteco y Oaxaca (Zapoteco de acuerdo con Sedlock et al., 1993 y Figura 1) fueron acrecionados durante el Cretácico Temprano con base en un análisis estratigráfico regional. Según este autor, la presencia de rocas continentales y marinas del Jurásico Medio (Grupo Tecocoyunca) en todo el terreno Mixteco y su ausencia aparente en el Zapoteco, y la existencia de capas rojas con variaciones transicionales a rocas carbonatadas del Cretácico Inferior cubriendo indistintamente a ambos terrenos, implica que dichos terrenos evolucionaron en contextos diferentes hasta su colisión en el Cretácico Temprano. González-Hervert et al. (1984) concluyeron lo mismo que Ramírez-Espinosa (1984) en un estudio estratigráfico del área de Caltepec-Metzontla (Figura 1), en el que enfatizaron la ausencia aparente de la Formación Matzitzi sobre el Complejo Acatlán y describieron capas rojas del Cretácico Inferior (conglomerado rojo Caltepec) como unidad de traslape sobre los complejos Acatlán y Oaxaqueño. González-Hervert et al. (1984) cartografiaron el contacto tectónico entre estos complejos como una zona muy angosta con un comportamiento sinuoso, aunque con rumbo general N-S, compuesta de micropliegues y fracturas en rocas del Complejo Acatlán y milonitas en las rocas precámbricas. La naturaleza del desplazamiento a lo largo del contacto no fue determinada.

Por otro lado, según los trabajos exploratorios de PEMEX en la región de Tlaxiaco, Oaxaca, los complejos Acatlán y Oaxaqueño están yuxtapuestos por la falla de Tamazulapan (López-Ticha, 1985). La falla de Tamazulapan (falla de Caltepec en la Figura 1) fue descrita como una gran estructura relacionada con la "consolidación" antigua de terrenos, y considerada como una frontera tectónica entre dos ámbitos geológicos con basamentos propios y coberturas precretácicas sedimentarias distintas (LópezTicha, 1985). Aunque gran parte de la traza de la falla de Tamazulapan es inferida, en la región de Tlaxiaco se describió con un rumbo general N-S y con movimiento lateral izquierdo. Su carácter izquierdo, como reactivación laramídica, se infirió por el arco estructural y cabalgaduras asociadas que se observan en la sierra del Tentzo, al sur de Puebla, al considerar que la prolongación septentrional de la falla se extiende hasta esta localidad (López-Ticha, 1985). Una reactivación posmiocénica de la falla de Tamazulapan fue también documentada (Torres-Torres et al., 1984). La reactivación fue descrita como un fallamiento lateral con componente derecha transpresiva afectando a las rocas volcánicas del área de Tamazulapan. Meneses-Rocha et al. (1994) interpretaron que la falla de Tamazulapan fue reactivada durante la orogenia Laramide como una falla inversa de ángulo alto. Más recientemente esta falla fue documentada cartográficamente (González-Ramos et al., 2000) como una falla lateral sinestral, y como límite tectónico entre los terrenos Mixteco y Oaxaca, cuyo trazo, en general N-S, vuelve a ser en gran parte inferido. Es de mencionarse que la falla de Tamazulapan coincide con la prolongación meridional de la falla de Caltepec en el área de San Juan Teita, al SE de Tlaxiaco (Figura 1).

A principios de los años 90, Yañez et al. (1991) concluyeron que la yuxtaposición de los complejos Acatlán 
y Oaxqueño fue el resultado de la colisión LaurenciaGondwana durante la orogenia Acadiana en el Devónico Medio. Esta interpretación fue sustentada con datos geocronológicos e isotópicos de las unidades del Complejo Acatlán, y en la suposición de que ambos complejos fueron intrusionados y ligados por los Granitoides Esperanza, unidad sinorogénica de la que se obtuvo una edad U-Pb (circón) de intersección inferior de $371 \pm 34 \mathrm{Ma}$ (Yañez et al., 1991). Poco tiempo después, en congruencia con esta idea, el límite tectónico entre los terrenos Mixteco y Zapoteco fue interpretado como una sutura devónica producto de la colisión entre los complejos Acatlán y Oaxaqueño (Sedlock et al., 1993; Ortega-Gutiérrez, 1993). Según estos autores, el evento de colisión ocasionó la intensa deformación dúctil, el metamorfismo y magmatismo sintectónico en el Complejo Acatlán. De acuerdo con Sedlock et al. (1993), la colisión probablemente ocurrió en un límite continental con una componente convergente en un contexto oceánico al sur del borde oriental de Norteamérica (Laurencia), pero en un escenario paleozoico de tectónica de placas incierto. Ortega-Gutiérrez (1993) interpretó el contacto entre los complejos como una sutura poliorogénica compleja en la que la yuxtaposición original de ambos ocurrió en el Devónico a lo largo de una estructura mayor subhorizontal en la que el Complejo Oaxaqueño, como corteza continental, cabalgó al Complejo Acatlán. La sutura involucró una napa compuesta por rocas ígneas ofiolíticas y sedimentarias eclogitizadas y los Granitoides Esperanza de afinidad continental, cuyo emplazamiento sintectónico selló y fechó la napa como elemento acadiano (Ortega-Gutiérrez, 1993).

En trabajos más recientes (Elías-Herrera y OrtegaGutiérrez, 1998, 2002), con base en cartografía geológica, análisis estructural y de microtectónica en muestras orientadas, y estudios petrográficos y geocronológicos, el contacto entre los basamentos cristalinos Acatlán y Oaxaqueño en el área de Caltepec fue reconocido como un borde tectónico más complejo (Figura 2). La edad, cinemática y dimensiones de la zona de contacto resultaron ser muy distintas a las previamente consideradas, lo cual modifica radicalmente la visión que se tenía de esta frontera geológica. Para los propósitos de este estudio en la Figura 3 se presenta el mapa geológico de la zona de falla de Caltepec, y en las Figuras 4 y 5 se muestran detalles geológico-estructurales de esta zona de falla modificados de Elías-Herrera y Ortega-Gutiérrez (2002).

\section{Falla de Caltepec}

El contacto tectónico entre los complejos Acatlán y Oaxaqueño al sur de Tehuacán, Puebla, en las áreas de Caltepec y Reyes Metzontla, únicos lugares donde éste aflora, fue reevaluado y redefinido como una zona de falla mayor retrabajada, con deformación dúctil y frágil sobrepuestas, con rumbo N-S y NNW, un espesor de 2 a 6 $\mathrm{km}$, y con una estructura en media flor (half-flower structure) en sección transversal (Elías-Herrera y Ortega-Gutiérrez, 1998, 2002). La zona de falla (Figuras 2 y 3), de oriente a poniente, consiste en 100-500 $\mathrm{m}$ de gneises granulíticos proterozóicos con retrogresión intensa dislocados por fallas subverticales; $200-500 \mathrm{~m}$ de milonita con foliación vertical, con protolito gnéisico y con cataclasis posterior; $50-800 \mathrm{~m}$ de una cuña tectónica de conglomerado paleogénico con clastos de esquisto, granito deformado, caliza fosilífera cretácica, pedernal, cuarzo, y escasos fragmentos de gneis; bordeado y basculado por fallamiento vertical; 2-4 km de un granito (granito Cozahuico) milonitizado con una foliación que varía de vertical a moderadamente inclinada hacia el ENE, con cataclasis posterior, y que cabalga hacia el poniente al Complejo Acatlán (Figuras 4 y 5); y por último, un sector indefinido de esquisto de mica-granate del Complejo Acatlán con una estructura fuertemente planar dislocados por fallamiento posterior subyacente al granito Cozahuico. El sentido de la cizalla en la deformación dúctil (milonitización) de los gneises proterozoicos y del granito Cozahuico es derecha, y fue deducida por medio de porfidoclastos tipo delta y sigma, geometría de granos cristalinos, microestructuras S-C, y deslizamiento antitético en granos minerales a escala meso y microscópica. La componente de contracción por el cabalgamiento del granito Cozahuico sobre el Complejo Acatlán en régimen dúctil, aunada a la cizalla derecha, indica que la falla de Caltepec corresponde a una estructura mesocortical mayor transpresiva, al menos en una parte de su historia de deformación dúctil. Aunque la cinemática derecha en la zona de falla (Figuras 3,4 y 5 ) es ambigua en términos de describir una contracción derecha debido a que la orientación de la foliación y la lineación de elongación mineral está afectada por deformación frágil posterior, la componente de contracción relacionada con el cabalgamiento fue deducida esencialmente por medio de meso y microestructuras en esquistos miloníticos a lo largo del contacto tectónico con el granito. Este aspecto se discute con detalle más adelante. Rasgos adicionales sobre la petrografía, relaciones texturales, e implicaciones de los diferentes sectores litológicos que conforman la zona de falla de Caltepec están documentados en Elías-Herrera y Ortega-Gutiérrez (2002).

\section{Complejo Oaxaqueño}

Al oriente, fuera de la zona de falla, el Complejo Oaxaqueño está conformado por bandas de gneises granulíticos gabróico-dioríticos y tonalíticos alternados con bandas de gneises graníticos (Figura 6a) con facies pegmatíticas en algunos lugares. La asociación mineral granulítica en los gneises gabróicos consiste en plagioclasa + clinopiroxena + ortopiroxena + granate + anfíbol titanífero + biotita titanífera \pm cuarzo \pm ilmenita. La ortopiroxena está reemplazada por bastita. La mineralogía en los gneises 
graníticos es cuarzo + feldespato potásico pertítico + plagioclasa + granate + biotita titanífera \pm ilmenita \pm allanita. Estructuralmente los gneises se caracterizan por un bandeamiento con rumbo general NW-SE con una inclinación subvertical al SW y NE, y una lineación de elongación mineral con una inclinación general de $20-50^{\circ}$ al NW. Los gneises están dislocados y brechados localmente en algunos lugares debido a un fallamiento frágil N-S de ángulo alto (Figura 6b). Muy cerca de la zona de falla de Caltepec, el bandeamiento gnéisico es gradualmente transpuesto por una foliación milonítica subvertical y un rumbo NNW, y por zonas de cizalla dúctil trenzadas de hasta un metro de espesor (Figura 6c). Los gneises granulíticos máficos en las zonas de cizalla dúctil son transformados a milonitas anfibolíticas. La fábrica gnéisica es sobrepuesta por una fábrica planar desarrollada por la reducción de grano debido a recristalización y alineación de anfíbol verde acicular y granos cuarzofeldespáticos. Relaciones texturales del anfíbol y plagioclasa en las milonitas indican un sentido de cizalla derecho (Figura 6d).

El Complejo Oaxaqueño al oriente de la zona de falla de Caltepec está cubierto discordantemente por la Formación Matzitzi, capas rojas (conglomerado Caltepec) del Cretácico Inferior, conglomerados paleogénicos, y rocas volcánicas y sedimentarias lacustres cenozoicas. De hecho, todas estas rocas de cobertura también cubren discordantemente al Complejo Acatlán al poniente de la zona de falla. La Formación Matzitzi, como unidad sedimentaria de traslape más antigua, es una restricción estratigráfica fundamental para la yuxtaposición tectónica de los complejos metamórficos. Esta formación es una secuencia de conglomerados, areniscas y limolitas con facies de litoral y continentales muy rica en flora fósil. Por la descripción de su flora se le asignó anteriormente una edad pensilvánica (Silva-Pineda, 1970), o bien una edad ambigua del Pensilvánico-Pérmico (Weber et al., 1987). Una década después, debido al descubrimiento de una planta fósil de las gigantopteridales, Lonesomia mexicana Weber,sp.nov., la Formación Matzitzi fue reasignada al leonardiano (Weber, 1997), lo cual parece ser corroborado por la similitud de la flora de Matztzi con estratos leonardianos de Texas. La yuxtaposición tectónica de los complejos metamórficos Acatlán y Oaxaqueño es, por lo tanto, preleonardiana (pre-Pérmico temprano tardío) y parece haber ocurrido más cerca del borde laurenciano que del gondwánico, como lo sugiere la flora leonardiana de la unidad de traslape.

En las partes aledañas al rancho Santa Lucía, $6 \mathrm{~km}$ al SSE de Coatepec (Figura 3), el Complejo Oaxaqueño está cubierto discordantemente por capas rojas del Cretácico Inferior. Las capas rojas consisten en conglomerados y areniscas con estratificación cruzada, con fragmentos de gneises del complejo subyacente, granitos, areniscas de la Formación Matzitzi, y rocas volcánicas, y se intercalan gradualmente con margas y limolitas fosilíferas de la Formación Zapotitlán del Barremiano (Calderón-
García, 1956). Estas mismas capas rojas están cubriendo discordantemente a gneises, al granito Cozahuico y a esquistos del Complejo Acatlán en el área de CaltepecMetzontla, en donde han sido descritos informalmente como "unidad de conglomerados rojos" (González-Hervert, 1984), "conglomerado rojo Caltepec" (Hernández-Lascares, 2000) o "formación Metzontla" (García-Duarte, 1999). Los gneises cubiertos por las capas rojas en el área de Caltepec corresponden a bloques xenolíticos contenidos en el granito Cozahuico dentro de la zona de falla de Caltepec, y no a gneises granulíticos del Complejo Oaxaqueño in situ, como se discute más adelante.

\section{Complejo Acatlán}

Al poniente, fuera de la zona de falla, el Complejo Acatlán consiste esencialmente en esquisto de mica, esquisto anfibolítico, esquisto cuarzofeldespático, esquisto verde, cuarcita, lentes de mármol, y algunos cuerpos de serpentina. El complejo metamórfico está cubierto discordantemente por sedimentos lacustres y rocas volcánicas terciarias, y localmente se observa debajo de las capas rojas del Cretácico Inferior en las áreas de Caltepec y San Simón Tlacuilotepec, y de la Formación Matzitzi en Metzontla. En las rocas micáceas del Complejo Acatlán la asociación mica blanca + biotita + granate, con clorita y epidota como fases retrogresivas, está ampliamente difundida. En los esquistos anfibolíticos la asociación hornblenda \pm plagioclasa \pm epidota \pm cuarzo sugiere que el metamorfismo regional alcanzó por lo menos la parte baja de la facies de anfibolita. Más aún, en algunas anfibolitas la asociación anfíbol sódico-cálcico (?) (pleocroismo verde azulado $)+$ epidota ( \pm zoisita $)+$ rutilo sugiere un metamorfismo en facies de anfibolita de alta presión. En el esquisto micáceo, porfidoblastos de granate son abundantes y presentan una relación textural compleja que sugiere una cristalización pre y sintectónica con la foliación dominante. No sólo en el esquisto micáceo, sino también en anfibolitas es común observar microscópicamente foliación metamórfica muy plisada. A escala de afloramiento las rocas presentan evidencias de polideformación, con patrones de superposición de pliegues indicando por lo menos dos fases de plegamiento (Figura 6e), cuya orientación y vergencia aún no han sido determinadas. Sin embargo, las rocas del Complejo Acatlán cerca y a lo largo del contacto tectónico con el granito Cozahuico presentan una fábrica completamente planar, con una foliación que se traspone a las anteriores. Por ejemplo, en el cañón de Cozahuico la foliación transpuesta en esquisto micáceo es definida por la reorientación y recristalización de mica blanca, biotita, granate y cuarzo, y tiene un rumbo NNW con inclinación moderada hacia el NE (Figura 4). Esta foliación es paralela a los planos axiales de pliegues menores asimétricos apretados con vergencia hacia el poniente y a la foliación milonítica del granito Cozahuico sobreyacente, mientras 


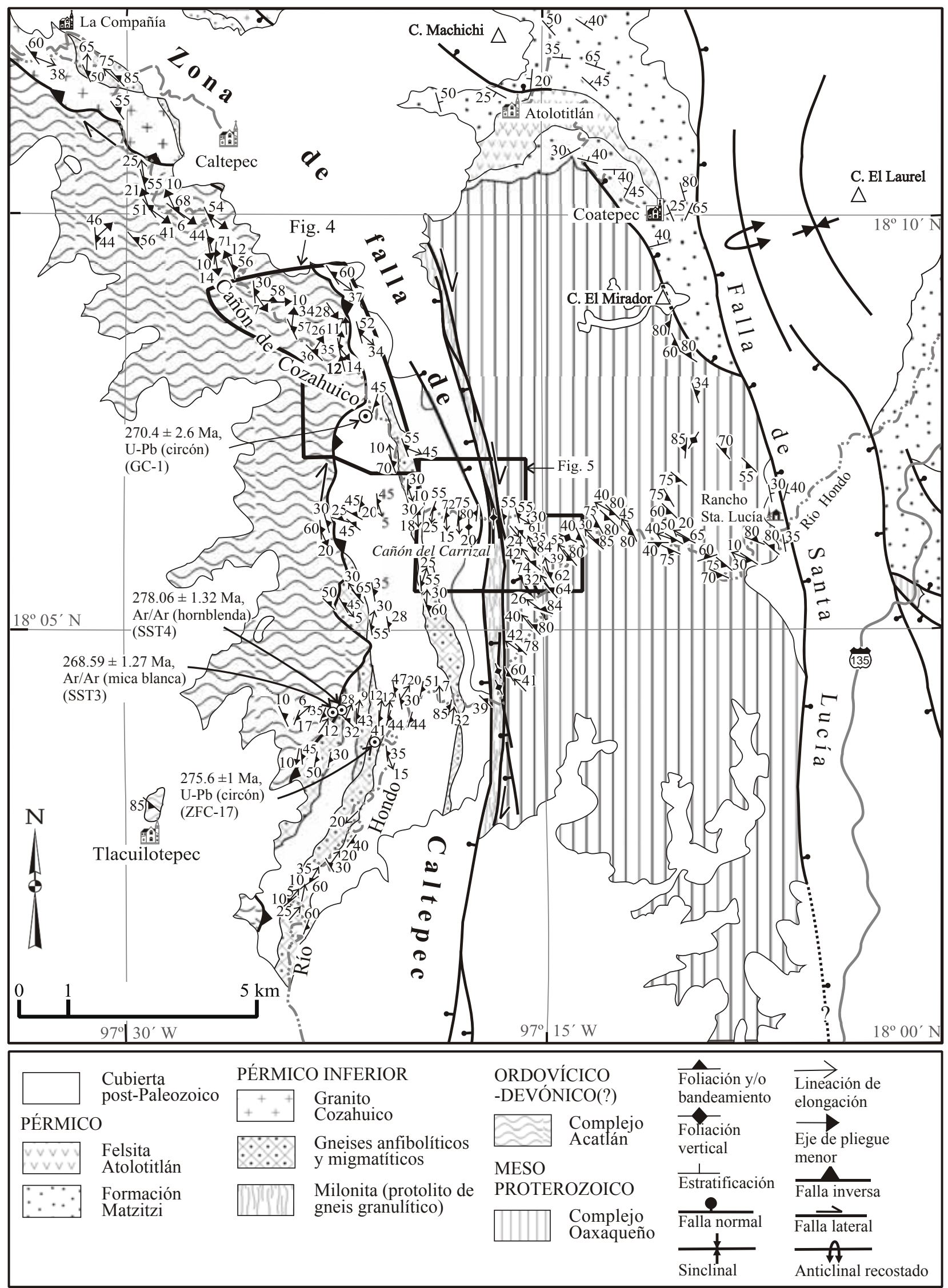

Figura 3. Mapa geológico del área de Caltepec, área singular por ser la única localidad donde está expuesta la zona de contacto tectónico entre los complejos cristalinos Acatlán y Oaxaqueño. Las rocas de cobertura pospaleozóica no fueron diferenciadas. 


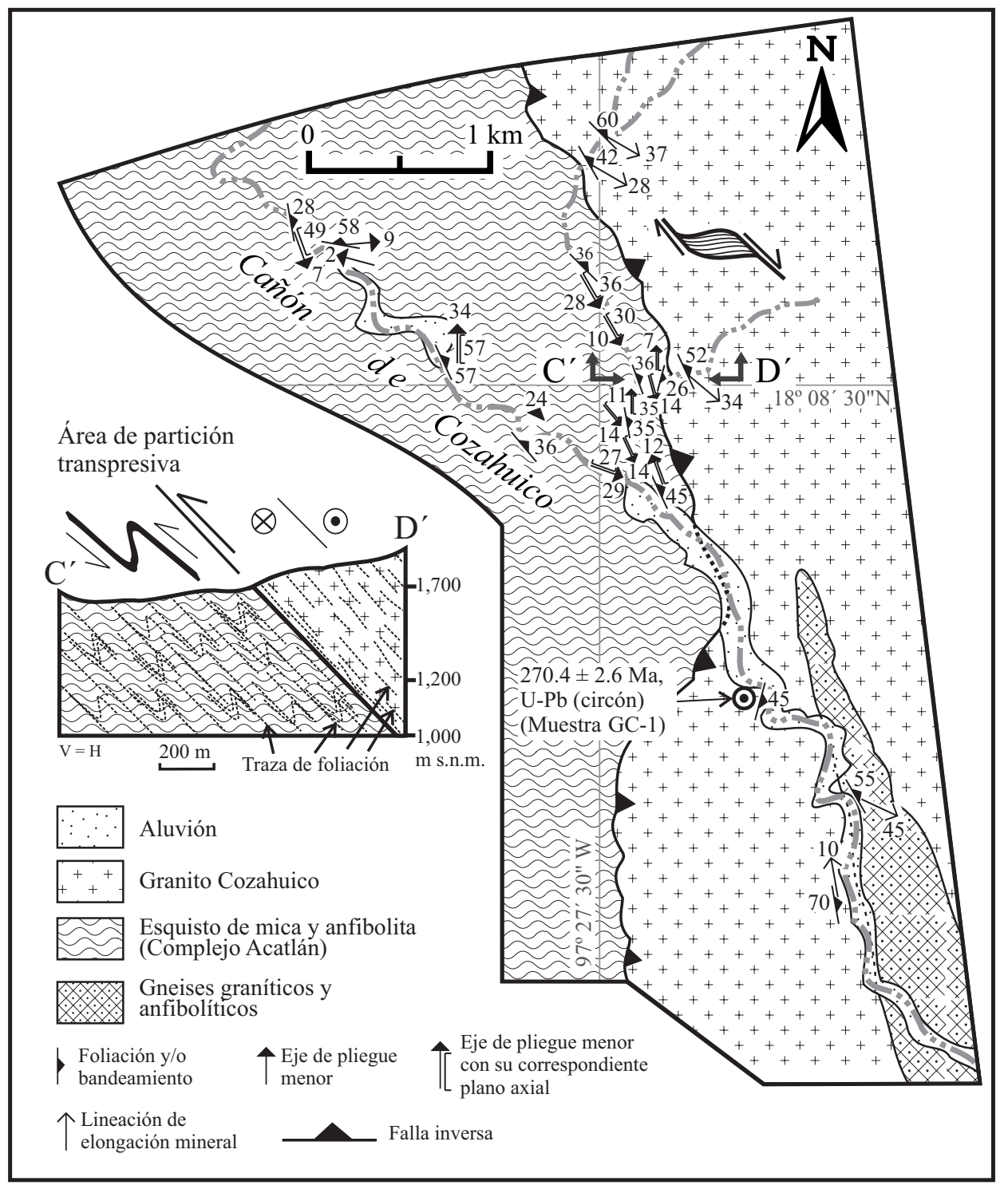

Figura 4. Detalle geológico-estructural del borde poniente de la zona de falla de Caltepec en el cañón de Cozahuico. La cinemática derecha en el granito Cozahuico se ilustra de manera esquemática por medio de una geometria tipo mica fish. Para su localización ver la Figura 3.

que los ejes de pliegues menores son paralelos a la lineación de elongación mineral del granito. En el área del río Hondo, un esquisto de cuarzo-mica blanca-granate milonítizado está estructuralmente subyaciendo al granito Cozahuico y a gneises anfibolíticos encajonados en el granito. En este caso, la lineación mineral del esquisto es burdamente paralela a la lineación de elongación del gneis y del granito. Granos de mica en forma de pez (mica fish) y microestructuras $\mathrm{S}-\mathrm{C}$ en el esquisto milonítico indican una dirección de movimiento de cima hacia el WSW, lo cual es consistente con la dirección de transporte tectónico hacia el $\mathrm{W}$ indicado por la vergencia de los pliegues menores en el esquisto del cañón de Cozahuico. Una relación de intrusión entre el granito Cozahuico y las rocas del Complejo Acatlán no fue observada. Con base en estos datos de campo se considera que el borde occidental de la zona de falla de
Caltepec es por lo tanto una falla inversa con deformación dúctil asociada.

\section{Granito Cozahuico}

El granito Cozahuico (Figura 6f y g) aflora en el cañón del mismo nombre, y es un plutón leucocrático de grano medio a grueso extremadamente alargado, con sus bordes delimitados por fallas, que se extiende a lo largo y dentro de la zona de falla de Caltepec. Por la relación de campo el granito es una unidad esencial en el entendimiento de la deformación dúctil de la falla de Caltepec. El borde oriental del granito es un contacto por falla normal (estructura frágil de reactivación cenozoica) con el conglomerado paleogénico y con una zona vertical de milonita; el borde 
occidental es un contacto de cabalgadura con deformación dúctil asociada. Su distribución a lo largo del contacto de falla sugiere que su emplazamiento pudo haber ocurrido a lo largo de una zona de debilidad (Ortega-Gutiérrez, 1975). Debido a su deformación interna, el plutón presenta una estructura de augengneis, por lo que originalmente fue considerado como parte del Complejo Acatlán, al correlacionarlo con los Granitoides Esperanza (OrtegaGutiérrez, 1975) en los que la estructura porfidoclástica es una característica importante. El granito Cozahuico es, sin embargo, diferente a los Granitoides Esperanza en términos petrográficos, geoquímicos, isotópicos y geocronológicos. El granito Cozahuico tiene una estructura compleja conformada por una mezcla de minerales ígneos, metamórficos y de alteraciones tardías relacionada con cataclasis posterior. Los minerales primarios son feldespato potásico, cuarzo, plagioclasa, biotita, hornblenda, ilmenita, titanita, allanita/epidota, apatita y circón. Si bien la epidota metamórfica y de alteración hidrotemal es abundante en el granito, en los casos de cristales euédricos a subédricos con zoneamiento oscilatorio de crecimiento alrededor de núcleos de allanita, y en cristales euédricos aislados dentro de fenocristales no alterados de ortoclasa en sectores no deformados del granito, la epidota se considera de origen magmático (e.g., Zen y Hammarstrom, 1984; Keane y Morrison, 1997). La orientación de cristales tabulares euédricos grandes (0.3-3 cm de largo) de feldespato potásico y plagioclasa con las maclas de crecimiento paralelas a las caras cristalinas, y cristales de tamaño medio de biotita, ilmenita y allanita/epidota definen una foliación magmática. La mineralogía metamórfica que define una foliación tectónica, o de estado sólido, consiste en cuarzo finamente recristalizado, biotita, microclina, mica blanca, albita, epidota, clinozoisita, y titanita, con abundancia de mirmequitas en los bordes de fenocristales de feldespato y a lo largo de esta foliación. En términos de microtectónica, la foliación en estado sólido se sobrepone paralelamente a la foliación magmática, lo que sugiere un emplazamiento sintectónico (e.g., Paterson et al., 1989; Miller y Paterson, 1994).

\subsection{Gneises y migmatitas en el granito Cozahuico}

El granito Cozahuico contiene bloques xenolíticos de gneises anfibolíticos, graníticos y migmatíticos bandeados con espesores que varían desde unos metros hasta 500 $\mathrm{m}$, y hasta $7 \mathrm{~km}$ de largo. Los bloques están alineados

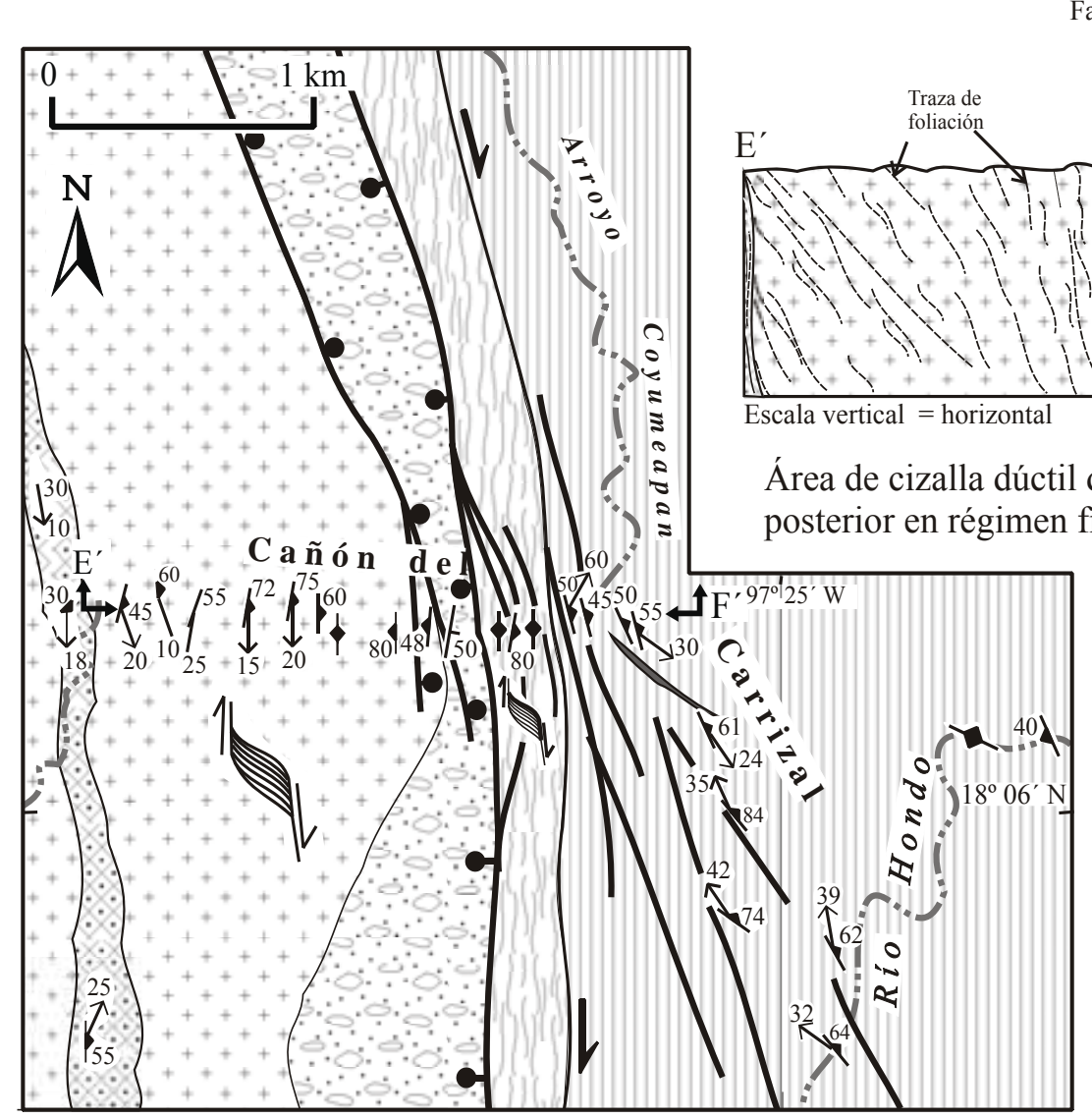

Fallas frágiles cenozoicas

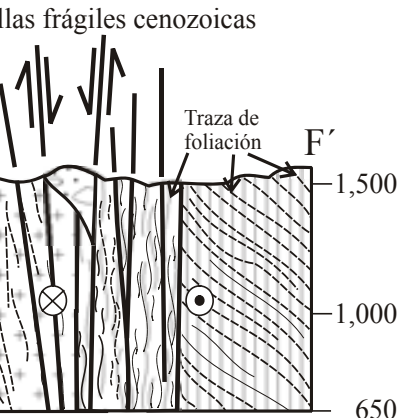

650 m s.n.m.

Área de cizalla dúctil derecha y retrabajo posterior en régimen frágil

Figura 5. Detalle geológico-estructural del borde oriental de la zona de falla de Caltepec en el cañón del Carrizal, sección tipo de esta zona de falla. La cinemática destral en el granito Cozahuico y en la milonita se ilustra de manera esquemática por medio de una geometria tipo mica fish. Para su localización ver la Figura 3. 
paralelamente al rumbo general N-S de la zona de falla y del granito Cozahuico, y presentan estructuras de boudinage a escalas macro (de mapa) y mesoscópica (de afloramiento). La fábrica de todos los gneises xenolíticos en general está también orientada paralela a la foliación magmática/tectónica y lineación mineral del granito encajonante, e inclusive con relaciones texturales o de fábrica indicando una cinemática derecha. Los gneises son similares a los del Complejo Oaxaqueño fuera de la zona de falla, con bandas máficas y félsica alternadas, con pequeños cuerpos lenticulares de mármol impuro con relaciones intrusivas a escala del bandeamiento circundante. Estos gneises, sin embargo, ya no presentan asociaciones mineralógicas de facies de granulita, las bandas máficas consisten en una asociación de hornblenda + plagioclasa + feldespato potásico \pm epidota \pm biotita, mientras que cuarzo monocristalino (localmente de color azulado) + listones de feldespato (principalmente microclina) policristalino + biotita constituyen las bandas félsicas. La relación de intrusión entre el granito Cozahuico y los gneises xenolíticos es clara, diques de granito deformado y no deformado cortan a los gneises, y localmente a lo largo del contacto con el plutón, los gneises presentan una zona de hibridación sugiriendo asimilación parcial de éstos por el granito.

Los gneises migmatíticos consisten en bandas (milimétricas hasta $50 \mathrm{~cm}$ de espesor) alternadas de melanosoma rico en hornblenda, biotita y epidota, y leucosoma granítico como parte del neosoma (Figura 6h). Gneises graníticos, granodioríticos y tonalíticos ricos en hornblenda conforman el paleosoma. Localmente se observan schlieren, estructuras plegadas y estructuras flebíticas de leucogranito. El neosoma granítico en las migmatitas es un granito con epidota con una fábrica hipidiomórfica granular en las que la microclina y texturas mirmequitas son abundantes. La epidota en el granito anatéctico se presenta en pequeños cristales (0.1-0.6 mm de largo) con contactos en bahía asociada a feldespato potásico, plagioclasa y cuarzo; en intercrecimiento vermiculítico a mirmequítico con cuarzo; y en cristales euédricos y subédricos con núcleos de allanita en feldespato y asociados a biotita. La epidota también presenta estabilidad textural en el melanosoma y en gneises granodioríticos bandeados ricos en hornblenda, sugiriendo un equilibrio térmico entre el leucosoma granítico y las unidades migmatíticas máficas. Es importante señalar que la asociación mineral en el neosoma es similar a la mineralogía primaria del granito Cozahuico, con epidota magmática en ambos casos, y que bandas o diques plegados del granito están estrechamente alternadas con las migmatitas bandeadas, por lo que la asociación petrogenética migmatitas-granito Cozahuico es claramente sugerida.

Con base en los datos estructurales y petrográficos, se considera que los bloques de gneises son megaxenolitos de gneises granulíticos proterozoicos que fueron fuertemente deformados y térmicamente reequilibrados por metamorfis- mo y fusión parcial en facies de anfibolita durante el emplazamiento del granito Cozahuico. La deformación dúctil, el metamorfismo, la migmatización, y el magmatismo con epidota primaria dentro de la zona de falla de Caltepec han sido por lo tanto interpretados como fenómenos simultáneos que ocurrieron en las raíces profundas de este límite tectónico (Elías-Herrera y Ortega-Gutiérrez, 2000, 2002). En este caso la deformación penetrante, recristalización y la fusión parcial probablemente fueron promovidas simultáneamente por la canalización y movilización de fluidos a lo largo de capas o bandas, proceso que es común en rocas fuertemente foliadas o en migmatitas bandeadas (Mawer et al., 1988). El magma anatéctico en la falla fue probablemente generado a presiones mínimas de $\sim 4.5 \mathrm{~kb}$ (16-17 km de profundidad) y con una presión de $\mathrm{H}_{2} \mathrm{O}$ alta sugerida por la presencia de epidota magmática (e.g., Schmidt y Thompson, 1996). Los fluidos y el calor necesario para rehomogeneizar y fundir gneises granulíticos posiblemente fueron derivados localmente de la deshidratación, en niveles corticales más profundos, del Complejo Acatlán cabalgado, o por procesos regionales asociados con una zona convergente oblicua (e.g., Saint Blanquat et al., 1998), postulada al poniente del Complejo Acatlán para tiempos premesozoicos (Elías-Herrera y Ortega-Gutiérrez, 2002). La inversión tectonotérmica que se observa en el cabalgamiento de gneises migmatíticos (metamorfismo de facies de anfibolita en su parte alta) sobre esquistos del Complejo Acatlán (metamorfismo de esquisto verde esencialmente) puede indicar un desplazamiento vertical grande y un traslape cortical importante en el borde poniente de la zona de falla. El cabalgamiento que se observa en los niveles de exposición actuales probablemente corresponde a un estadío de este evento tectonomagmático durante la etapa tardía de enfriamiento sintectónico del granito Cozahuico. Así lo sugieren la deformación dúctil y el metamorfismo de facies de esquisto verde-parte baja de la facies de anfibolita de los esquistos del Complejo Acatlán a lo largo de la zona de falla.

\subsection{Naturaleza sintectónica del granito Cozahuico}

El emplazamiento sintectónico de plutones es un aspecto controversial en el que se han señalado dudas importantes sobre el significado de la relación espacial estrecha entre plutones y fallas (Paterson y Schmidt, 1999). Los criterios para definir la naturaleza sintectónica de intrusiones ígneas son comúnmente ambiguos, requiriéndose casi siempre líneas de argumentación múltiples (Paterson y Tobisch, 1988; Paterson et al., 1989; Miller y Paterson, 1994). No obstante estas dificultades, el emplazamiento y la deformación dúctil del granito Cozahuico a lo largo de la falla de Caltepec como fenómenos simultáneos se sustenta en la siguiente argumentación: (1) La forma exageradamente elongada, con 2-6 km de ancho por más de $25 \mathrm{~km}$ de largo, del plutón deformado, con su eje mayor paralelo a la 

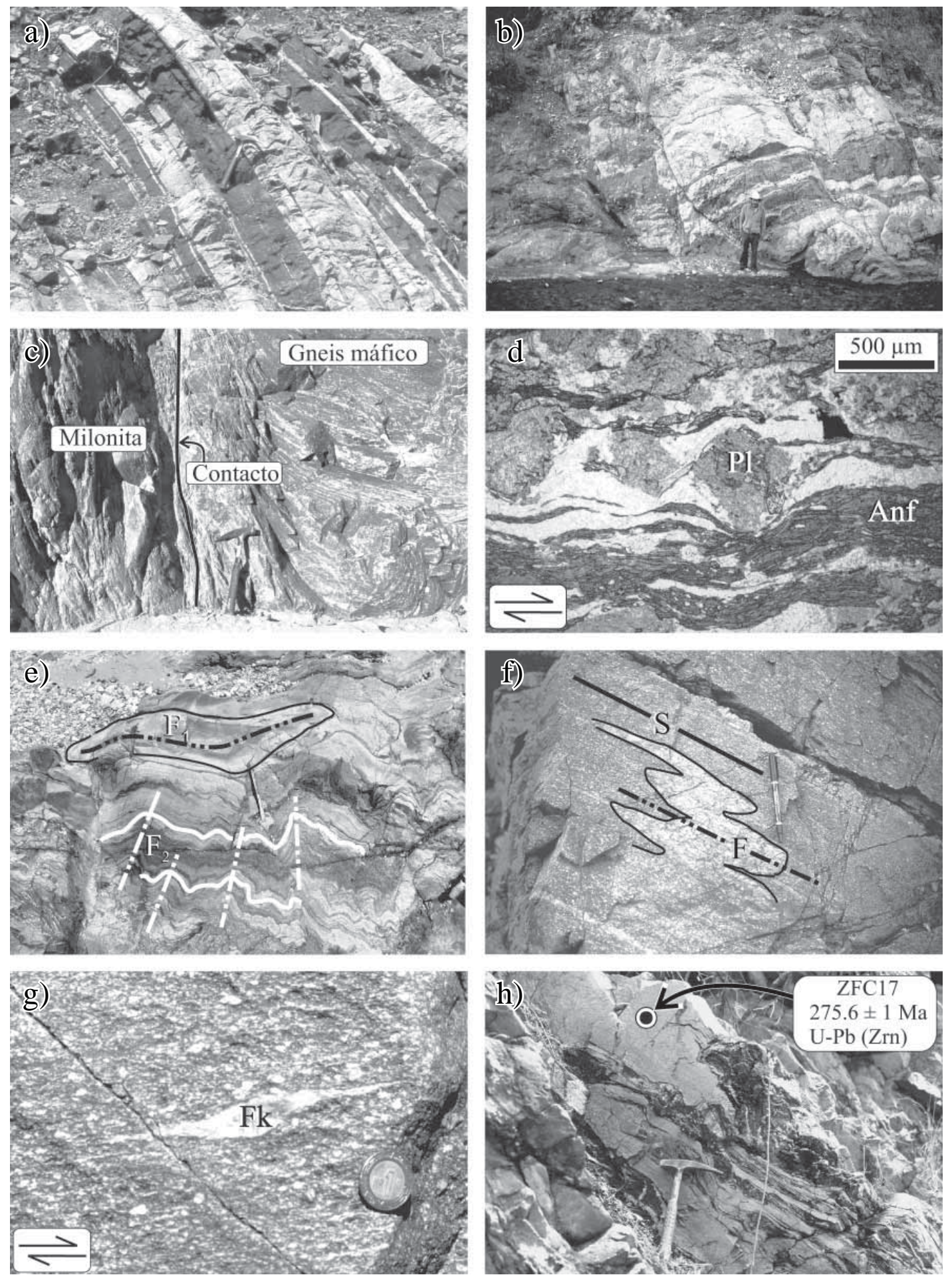

Figura 6. (a) Bandas alternadas de gneises gabróicos-dioríticos y graníticos del Complejo Oaxaqueño en el río Hondo, al oriente de la falla de Caltepec. (b) Gneises del Complejo Oaxaqueño dislocados por fallas normales cenozoicas en el cañón del Carrizal, cerca de la zona de falla de Caltepec. (c) Gneis granulítico gabróico-diorítico que por cizalla dúctil es transformado a una milonita anfibolítica con foliación vertical que se sobrepone al bandeamiento gnéisico, cañón del Carrizal, borde oriental de la zona de falla de Caltepec. (d) Milonita anfibolítica a escala microscópica de la porción oriental de la zona de falla de Caltepec; las relaciones texturales del anfíbol (Anf) y de plagioclasa ( $\mathrm{Pl}$ ) en la milonita indican un sentido de cizalla derecha. (e) Metasedimentos del Complejo Acatlán con al menos dos fases de plegamiento sobrepuestas: pliegue de funda $\mathrm{F}_{1}$ afectado por un plegamiento posterior $\mathrm{F}_{2}$. La localidad corresponde al cañón de Cozahuico, al poniente de la zona de falla de Caltepec; la escala es un cincel de $15 \mathrm{~cm}$ de largo. (f) Granito Cozahuico con una fase granítica más leucocrática plegada cuyos planos axiales (F) son paralelos a la foliación milonítica (S), cañón del río Hondo, zona de falla de Caltepec; la escala es un plumón de $12 \mathrm{~cm}$ de largo. (g) Granito Cozahuico con un porfidoclasto de feldespato potásico (Fk) tipo ó indicando cizalla derecha, cañón del Carrizal, zona de falla de Caltepec. (h) Gneises migmatíticos bandeados encajonados dentro del granito Cozahuico; bandas melanosoma ricas en anfíbol se alternan con bandas graníticas leucosomáticas, cuya edad U-Pb de una de ellas se señala. Localidad de la barranca Agua Salada, zona de falla de Caltepec. 
dirección principal de alargamiento, y sus bordes definidos por fallas a lo largo de un límite de terrenos, sugieren que su emplazamiento y expansión lateral fueron probablemente controlados por el rumbo de un fallamiento dúctil (e.g., Vigneresse, 1995; Román-Bardiel et al., 1997). (2) La foliación en el granito Cozahuico es concordante con la foliación compuesta en el esquisto subyacente al poniente, y los ejes de pliegues menores apretados con vergencia hacia el WSW en el esquisto son paralelos a la lineación de elongación mineral en el plutón. Si bien estas relaciones pueden ser ambiguas, el paralelismo estructural en este caso se interpreta como el resultado de una deformación dúctil simultánea del esquisto y el granito durante su etapa de enfriamiento. La foliación compuesta en el esquisto, en la zona de contacto tectónico con el granito, es una estructura planar que se sobrepone claramente a foliaciones anteriores en el esquisto. (3) La relación intrusiva del granito Cozahuico con relación a bloques alargados de gneises con estructuras de boudinage, vetillas de granito plegadas y con boudinage en los gneises xenolíticos, deformación dúctil heterogenea en vetillas graníticas con sectores fuerte y debilmente deformados, y plegamiento en los gneises xenolíticos con planos axiales paralelos a la foliación del granito circundante, son evidencias sólidas de magmatismo y deformación simultáneos. (4) La presencia, en el granito Cozahuico, de pegmatitas no foliadas, aplitas, y diques graníticos de grano medio a fino con foliación interna, con pliegues apretados a cerrados cuyos planos axiales son paralelos a la foliación milonítica del plutón encajonante (Figura 6f), indica que pulsos magmáticos tardíos ocurrieron durante el enfriamiento y la deformación del granito. (5) La deformación interna del plutón con zonas de cizalla microscópicas (estructuras S-C) a lo largo y ancho de éste, aunada a la ausencia de zonas de cizalla mesoscópicas entreveradas y alrededor de sectores poco deformados, son también rasgos consistentes con un emplazamiento sintectónico (e.g., Gapais, 1989). (6) La presencia de foliación magmática o submagmática y de estado sólido en arreglos paralelos son características diagnósticas de un emplazamiento sintectónico (Paterson et al., 1989; Miller y Paterson, 1994). Por otro lado, el aspecto termomecánico entre cizalla dúctil y magmatismo sintectónico es un problema importante y complejo (e.g., Brown y Solar, 1998; Harrison et al., 1998; Nabelek y Liu, 1999; Leloup et al., 1999) que, para el caso de la falla de Caltepec, no ha sido abordado hasta ahora.

\section{Geocronología: edad del granito Cozahuico, migmatitas y de la falla Caltepec}

Debido a que la naturaleza sintectónica del granito Cozahuico parece ser clara, y su emplazamiento entre basamentos metamóficos diferentes como plutón sellador (stitching pluton) probablemente ocurrió casi simultáneamente con la migmatización dentro de la falla de Caltepec, la edad tanto del granito como del neosoma en las migmatitas son evidentemente muy significativas. Aunque algunos datos geocronométricos e isotópicos relacionados con el granito Cozahuico fueron documentados anteriormente (Ruiz-Castellanos, 1979; Torres-Vargas et al., 1986; 1999), la trascendencia del plutón como elemento fundamental en la historia geológica de la falla de Caltepec y de la yuxtaposición de los basamentos cristalinos más importantes del sur de México no fue percibida plenamente. Así, por ejemplo, Ruiz-Castellanos (1979) obtuvo una línea de regresión $\mathrm{Rb}$-Sr (7 puntos de roca entera) de 269 $\pm 21 \mathrm{Ma}$ (Pérmico medio) con una relación inicial ${ }^{87} \mathrm{Sr} /{ }^{86} \mathrm{Sr}$ de 0.7056 para el granito deformado de la localidad La Compañía, en el área de Caltepec. Es conveniente señalar que "el granito de La Compañía" o "granito Caltepec", por continuidad de afloramiento corresponde claramente a la prolongación septentrional del granito Cozahuico. La edad pérmica $\mathrm{Rb}-\mathrm{Sr}$ fue interpretada ambiguamente como la edad de intrusión del granito o bien como la edad de la deformación "cataclástica" del mismo. El emplazamiento del plutón fue, sin embargo, considerado casi simultáneo a su deformación con base en las relaciones isotópicas (Ruiz-Castellanos, 1979).

Es interesante mencionar que esta primera inferencia sobre la relación sintectónica del granito y su edad $\mathrm{Rb}-\mathrm{Sr}$ del Pérmico vienen a ser congruentes con lo determinado estructural, petrográfica y geocronológicamente dos décadas después. Ruiz-Castellanos (1979) también concluyó que "el granito de La Compañía" es isotópicamente muy diferente a los augen-esquistos de la "Formación Esperanza" (Granitoides Esperanza) aflorando en otras partes del Complejo Acatlán. Por otro lado, "el granito de La Compañía" fue también fechado por K-Ar (biotita) con una edad del Jurásico Medio de $167 \pm 8$ Ma (Torres-Vargas et al., 1986), edad que más bien puede estar relacionada con el retrabajo de la zona de falla. Después, una edad devónica para el granito Cozahuico fue implicada al asumirse que los Granitoides Esperanza, fechados en el área de Acatlán por U-Pb (circón) en $371 \pm 34$ Ma (Yañez et al., 1991), estuvieron involucrados directamente en la yuxtaposición tectónica de los complejos Acatlán y Oaxaqueño en la zona de falla de Caltepec (Yañez et al., 1991; Sedlock et al., 1993; Ortega-Gutiérrez, 1993). Si embargo, de acuerdo con información geocronológica más reciente, la edad de los Granitoides Esperanza en su localidad tipo resultó ser del Ordovícico Tardío-Silúrico temprano (440 $\pm 14 \mathrm{Ma}$, Ortega-Gutiérrez et al., 1999), y la correlación entre el granito Cozahuico y los Granitoides Esperanza ha resultado ser también inválida a la luz de datos geológicos nuevos.

Por lo anterior, y debido a la falta de estudios isotópicos adecuados para establecer claramente la edad y deformación dúctil del granito Cozahuico y de la falla de Caltepec, se decidió fechar por U-Pb (circón) a este plutón (muestra GC1) y al neosoma granítico (muestra ZFC17) de las migmatitas en la zona de falla de Caltepec. Los resultados y los procedimientos analíticos resumidos 
se presentan en las Tablas 1 y 2 , y en los diagramas concordia $\mathrm{Pb} / \mathrm{U}$ tradicionales se muestran gráficamente los resultados (Figura 7). Del granito Cozahuico se obtuvieron seis fracciones de circones con edades discordantes (Tabla 1 y Figura 7a). Con todas las fracciones discordantes se obtuvieron edades de intersección inferior y superior muy pobremente definidas de $326 \pm 118$ Ma y $1137 \pm 257 \mathrm{Ma}$, respectivamente. Al excluir las dos fracciones con errores analíticos mayores se obtuvieron edades de intersección inferior y superior más definidas de $373 \pm 43 \mathrm{Ma} \mathrm{y}$ $1301 \pm 122 \mathrm{Ma}$, pero descartando las dos fracciones más discordantes las edades obtenidas fueron de $258 \pm 11$ Ma y $987 \pm 11 \mathrm{Ma}$ (Figura 7a). En cualquier caso, las edades de intersección superior del Mesoproterozoico se interpretan como la edad de la fuente de componentes radiogénicos heredados, mientras que las edades de intersección inferior se consideran correspondientes a la edad de cristalización del granito. Así, la edad de intersección inferior de $373 \pm 43$ Ma fue interpretada preliminarmente como la edad de emplazamiento del granito Cozahuico y de la interacción transpresiva de los bloques Acatlán y Oaxaqueño relacionados a la orogenia Acadiana (ElíasHerrera y Ortega-Gutiérrez, 1998), como previamente se había sugerido (Yañez et al., 1991). No obstante, la edad de $258 \pm 11$ Ma se aproxima más a la edad de cristalización del granito como se discute más adelante, y la edad de intersección superior correspondiente, $987 \pm 11 \mathrm{Ma}$, es más consistente con el evento tectonotérmico zapoteco granulítico del Complejo Oxaqueño (Solari et al., 2003), el cual es la fuente probable de los componentes heredados. Por la ambigüedad de los datos, los cuales varían en función de la combinación de fracciones, se considera que la edad del granito Cozahuico no quedó claramente establecida con las seis fracciones de circones analizadas.

Paralelamente a lo anterior, ocho fracciones de circones del neosoma granítico en los gneises migmatíticos fueron analizadas (Tabla 1). Algunas de estas fracciones resultaron ser menos discordantes, e inclusive una de ellas (C, W27) tiene una edad concordante de $275.6 \pm 1 \mathrm{Ma}$ (Figura $7 \mathrm{~b}$ ). El arreglo lineal de las fracciones discordantes define una

Tabla 1. Datos geocronológicos U-Pb (circón) para un leucogranito (neosoma) de gneises migmatíticos y el granito Cozahuico en la zona de la falla de Caltepec ${ }^{\mathrm{a}}$.

\begin{tabular}{|c|c|c|c|c|c|c|c|c|c|c|c|c|}
\hline \multirow[t]{2}{*}{ Fracción ${ }^{b}$} & \multirow{2}{*}{$\begin{array}{l}\text { Peso } \\
(\mathbf{m g})\end{array}$} & \multirow{2}{*}{$\begin{array}{c}\mathbf{U} \\
(\mathbf{p p m})\end{array}$} & \multirow{2}{*}{$\begin{array}{c}\mathbf{P b} \\
(\mathbf{p p m}) \\
\end{array}$} & \multicolumn{3}{|c|}{ Relaciones observadas $^{\mathrm{c}}$} & \multicolumn{3}{|c|}{ Relaciones atómicas ${ }^{\mathrm{e}}$} & \multicolumn{3}{|c|}{ Edades, $\mathrm{Ma}^{\mathrm{f}}$} \\
\hline & & & & ${ }^{206} \mathrm{~Pb} /{ }^{204} \mathrm{~Pb}$ & ${ }^{207} \mathrm{~Pb} /{ }^{206} \mathrm{~Pb}$ & ${ }^{208} \mathrm{~Pb} /{ }^{206} \mathrm{~Pb}$ & ${ }^{206} \mathbf{P b}{ }^{\mathrm{d} / 238} \mathbf{U}$ & ${ }^{207} \mathbf{P b}^{\mathrm{d} / 235} \mathbf{U}$ & ${ }^{207} \mathbf{P b}^{\mathrm{d} / 206} \mathbf{P b}^{\mathrm{d}}$ & ${ }^{206} \mathbf{P b}^{\mathrm{d} / 238} \mathbf{U}$ & ${ }^{207} \mathbf{P b}^{\mathrm{d} / 235} \mathbf{U}$ & ${ }^{207} \mathbf{P b}^{\mathrm{d}, \mathrm{g} / 206} \mathbf{P b}^{\mathrm{d}}$ \\
\hline \multicolumn{13}{|c|}{ Leucogranito (neosoma) en gneises migmatíticos; cañón del río Hondo, muestra ZFC17 } \\
\hline $\mathrm{A}, \mathrm{W} 27$ & 0.010 & 300 & 12.6 & 1,628 & 0.06069 & 0.07396 & $0.04421(0.3)$ & $0.31986(0.6)$ & $0.05247(0.6)$ & 279.0 & 282.0 & $306 \pm 10$ \\
\hline $\mathrm{B}, \mathrm{W} 13$ & 0.021 & 505 & 26.5 & 5,306 & 0.06134 & 0.08129 & $0.05377(0.8)$ & $0.43638(0.8)$ & $0.05886(0.1)$ & 338.0 & 368.0 & $562 \pm 2$ \\
\hline C,W27 & 0.015 & 909 & 39.7 & 926 & 0.06730 & 0.08845 & $0.04371(0.3)$ & $0.31179(0.4)$ & $0.05179(0.3)$ & 275.5 & 275.6 & $276.4 \pm 6$ \\
\hline $\mathrm{D}, \mathrm{W} 35$ & 0.005 & 879 & 78.0 & 3,452 & 0.07207 & 0.10168 & $0.08845(0.4)$ & $0.83295(0.4)$ & $0.06830(0.1)$ & 546.3 & 615.2 & $877.8 \pm 2$ \\
\hline F,W15 & 0.012 & 779 & 125.0 & 1,575 & 0.08455 & 0.16380 & $0.14872(0.4)$ & $1.55274(0.4)$ & $0.07576(0.1)$ & 893.5 & 951.6 & $1088.8 \pm 2$ \\
\hline G,W23 & 0.010 & 257 & 40.2 & 329 & 0.11474 & 0.28128 & $0.12569(0.6)$ & $1.24615(0.7)$ & $0.07210(0.3)$ & 761.7 & 822.0 & $988.9 \pm 6$ \\
\hline H,W13 & 0.009 & 495 & 82.8 & 363 & 0.11421 & 0.18344 & $0.14390(0.4)$ & $1.49635(0.5)$ & $0.07562(0.3)$ & 865.0 & 929.2 & $1084.9 \pm 6$ \\
\hline E,W7 & 0.011 & 244 & 29.4 & 2,674 & 0.07248 & 0.18491 & $0.11205(0.4)$ & $1.04414(0.4)$ & $0.06759(0.2)$ & 684.6 & 726.0 & $856.1 \pm 4$ \\
\hline \multicolumn{13}{|c|}{ Granito Cozahuico; cañón de Cozahuico, muestra GC-1 (Coza2) } \\
\hline $\begin{array}{l}\text { 1a, abr, elg, } \\
\text { dm (8 grn) }\end{array}$ & 0.103 & 123 & 9.5 & 55,748 & 0.0651 & 0.0614 & $02(0.4)$ & $0.71495(0.4)$ & $0(0.5)$ & .2 & 547.7 & $768.0 \pm 4$ \\
\hline $\begin{array}{l}\text { 3a, abr, elg, } \\
\text { dm (7 grn) }\end{array}$ & 0.023 & 155 & 10.4 & 3,835 & 0.0642 & 0.0708 & $0.06893(0.4)$ & $0.5746(0.4)$ & $0.06046(1.3)$ & 430.0 & 461.0 & $620.0 \pm 8$ \\
\hline $\begin{array}{l}\text { 3b, abr, stb, } \\
\text { dm (24 grn) }\end{array}$ & 0.024 & 259 & 26.3 & 75,135 & 0.0721 & 0.0997 & $0.10072(0.4)$ & $0.99834(0.4)$ & $0.07189(0.3)$ & 618.6 & 703.0 & $982.8 \pm 3$ \\
\hline $\begin{array}{l}\text { pm1, stb, abr, } \\
\text { (26 grn) }\end{array}$ & 0.021 & 626 & 50.0 & 24,144 & 0.0671 & 0.0615 & $0.08178(0.4)$ & $0.7498 \quad(0.4)$ & $0.06650(0.6)$ & 507.0 & 568.0 & $822.0 \pm 5$ \\
\hline $\begin{array}{l}\text { 1b, abr, dm } \\
(8 \text { grn })\end{array}$ & 0.035 & 184 & 12.6 & $3,=359$ & 0.0930 & 0.1574 & $0.116 \quad(2)$ & $1.116 \quad(2)$ & $0.0692 \quad(7)$ & 713.1 & 761.3 & $905.6 \pm 23$ \\
\hline $\begin{array}{l}2, \mathrm{dm} \\
(1 \mathrm{grn})\end{array}$ & 0.007 & 107 & 22.0 & 212 & 0.1490 & 0.2849 & 0.0895 & 0.818 & 0.0663 & 552.8 & 607.3 & $816.4 \pm 22$ \\
\hline
\end{tabular}

${ }^{a}$ Los análisis fueron hechos por Robert López en la Universidad de California, en Santa Cruz, Ca. ${ }^{\text {b }}$ Propiedades de las fracciones: grn, granos; abr, pulidos; dm, diamagnéticos; elg, alargados y delgados; stb, cortos y gruesos. ${ }^{\mathrm{C}} \mathrm{Las}$ relaciones istópicas observadas fueron corregidas por un fraccionamiento de masa de $1 \%$. Las fracciones fueron resaltadas con el trazador mezclado ${ }^{235} \mathrm{U} /{ }^{205} \mathrm{~Pb}$ y fueron corregidas por el efecto del trazador y del blanco. Los errores $2 \sigma$ en las relaciones ${ }^{207} \mathrm{~Pb} /{ }^{206} \mathrm{~Pb}$ y ${ }^{208} \mathrm{~Pb} /{ }^{206} \mathrm{~Pb}$ son $<0.8 \%$, generalmente mejores que $0.1 \%$; Los errores en la relación ${ }^{206} \mathrm{~Pb} /{ }^{204} \mathrm{~Pb}$ varían desde $0.3 \%$ hasta $1.9 \%$. ${ }^{\mathrm{d}} \mathrm{Pb}$ radiogénico. ${ }^{\mathrm{e}}$ Las constantes de decaimiento son: ${ }^{238} \mathrm{U}=1.55125 \times 10^{-10} ;{ }^{235} \mathrm{U}=9.48485 \times 10^{-10} ;{ }^{238} \mathrm{U} /{ }^{235} \mathrm{U}=137.88$. Los errores estimados de la relación atómica $\mathrm{U} / \mathrm{Pb}$ son $\pm 0.4 \%$ basados en análisis replica de una fracción de circón de cristal único. Los errores $(2 \sigma$, en \%) son presentados en paréntesis. ${ }^{\mathrm{f}}$ La disolución de circon y la química de intercambio iónico fueron modificadas de acuerdo con Krogh (1973) y Mattinson (1987), en microcápsulas del tipo usadas por Parrish (1987). La cantidad total procesada del blanco de Pb varió entre 2 pg y 30 pg, generalmente promediando $<10 \mathrm{pg}$. Las composiciones iniciales de $\mathrm{Pb}$ corresponden a análisis isotópicos de feldespatos seleccionados con relaciones 208:207:206:204 = 18.34:15.57:37.66:1. Los datos isotópicos fueron medidos en un espectrómetro de masas multicolector VG54-30 con un detector de conteo de pulsos Daly en la Universidad de California en Santa Cruz, Cal. ${ }^{\mathrm{g}}$ Los errores en las edades ${ }^{207} \mathrm{~Pb}^{\mathrm{d} / 206} \mathrm{~Pb}^{\mathrm{d}}$ son $2 \sigma$ según los programas para el procesamiento de datos isotópicos PBDAT de Ludwig (1991). 
Tabla 2. Datos geocronológicos U-Th-Pb de análisis puntuales por medio de microsonda iónica sensitiva de alta resolución (SHRIMP) en circones del granito Cozahuico (muestra GC-1) en la zona de falla de Caltepec ${ }^{\mathrm{a}}$.

\begin{tabular}{|c|c|c|c|c|c|c|c|c|c|c|}
\hline \multirow{2}{*}{$\begin{array}{c}\text { Granos/ } \\
\text { Puntos }\end{array}$} & \multirow{2}{*}{$\begin{array}{c}\text { Núcleos/ } \\
\text { Bordes }\end{array}$} & \multirow{2}{*}{$\begin{array}{c}\mathbf{U}^{\mathrm{b}} \\
(\mathbf{p p m})\end{array}$} & \multirow{2}{*}{$\begin{array}{c}\text { Th } \\
(\mathbf{p p m})\end{array}$} & \multirow[t]{2}{*}{$\mathbf{T h} / \mathrm{U}$} & \multirow{2}{*}{$\begin{array}{r}{ }^{206} \mathbf{P b}^{\mathbf{b}} \\
(\%)\end{array}$} & \multicolumn{3}{|c|}{ Relaciones atómicas $\mathrm{s}^{\mathrm{c}, \mathrm{d}}$} & \multirow{2}{*}{$\begin{array}{c}\text { Edades, } \mathrm{Ma}^{\mathrm{e}} \\
{ }^{206} \mathrm{~Pb} /{ }^{238} \mathrm{U}\end{array}$} & \multirow{2}{*}{$\begin{array}{c}\text { Discordancia }^{\mathbf{f}} \\
(\%)\end{array}$} \\
\hline & & & & & & ${ }^{206} \mathrm{~Pb} /{ }^{238} \mathrm{U}$ & ${ }^{207} \mathbf{P b} /{ }^{235} \mathbf{U}$ & ${ }^{207} \mathrm{~Pb} /{ }^{206} \mathrm{~Pb}$ & & \\
\hline GC1-1 & Borde & 127 & 7 & 0.06 & 0.612 & $0.04107(2.97)$ & $0.32816(33.44)$ & $0.05795(33.31)$ & $257 \pm 4$ & \\
\hline GC1-18 & Borde & 114 & 18 & 0.15 & 0.160 & $0.04153(1.63)$ & $0.29261(4.18)$ & $0.05110(3.84)$ & $262 \pm 4$ & \\
\hline GC1-8 & Borde & 70 & 4 & 0.06 & 0.433 & $0.04201(2.05)$ & $0.27891(8.13)$ & $0.04815(7.87)$ & $266 \pm 5$ & \\
\hline $\mathrm{GC} 1-4$ & Borde & 121 & 4 & 0.03 & 0.478 & $0.04252(1.75)$ & $0.33691(4.06)$ & $0.05746(3.67)$ & $267 \pm 5$ & \\
\hline GC1-3 & Borde & 268 & 1 & 0.00 & 0.109 & $0.04240(1.51)$ & $0.31214(2.97)$ & $0.05339(2.56)$ & $267 \pm 4$ & \\
\hline GC1-20 & Borde & 111 & 4 & 0.04 & 0.090 & $0.04266(1.66)$ & $0.31774(3.78)$ & $0.05402(3.40)$ & $268 \pm 4$ & \\
\hline GC1-17 & Borde & 231 & 48 & 0.21 & 0.246 & $0.04297(1.46)$ & $0.32189(2.64)$ & $0.05434(2.20)$ & $270 \pm 4$ & \\
\hline GC1-11 & Borde & 293 & 3 & 0.01 & 0.118 & $0.04305(1.49)$ & $0.31715(2.83)$ & $0.05343(2.40)$ & $271 \pm 4$ & \\
\hline GC1-7 & Borde & 106 & 4 & 0.04 & -0.031 & $0.04388(1.93)$ & $0.36428(9.56)$ & $0.06021(9.36)$ & $274 \pm 5$ & \\
\hline GC1-5 & Borde & 104 & 4 & 0.04 & -0.136 & $0.04322(1.80)$ & $0.28412(6.27)$ & $0.04768(6.00)$ & $274 \pm 5$ & \\
\hline GC1-19 & Borde & 271 & 3 & 0.01 & 0.051 & $0.04374(1.45)$ & $0.32654(3.43)$ & $0.05415(3.10)$ & $275 \pm 4$ & \\
\hline GC1-21 & Borde & 272 & 5 & 0.02 & -0.174 & $0.04381(1.44)$ & $0.30815(2.56)$ & $0.05101(2.12)$ & $277 \pm 4$ & \\
\hline GC1-6 & Borde & 612 & 62 & 0.10 & -0.208 & $0.04520(1.38)$ & $0.30605(2.29)$ & $0.04911(1.82)$ & $286 \pm 4$ & \\
\hline GC1-2 & Núcleo & 136 & 14 & 0.10 & 0.847 & $0.11111(1.56)$ & $1.04526(2.63)$ & $0.06823(2.12)$ & $674 \pm 10$ & 29 \\
\hline GC1-15 & Núcleo & 178 & 87 & 0.49 & 0.723 & $0.11618(1.41)$ & $1.11912(2.16)$ & $0.06986(1.64)$ & $703 \pm 10$ & 30 \\
\hline GC1-9 & Núcleo & 1145 & 103 & 0.09 & 0.361 & $0.14529(1.32)$ & $1.41515(1.49)$ & $0.07064(0.68)$ & $872 \pm 11$ & 8 \\
\hline GC1-12 & Núcleo & 698 & 81 & 0.12 & 0.436 & $0.14690(1.48)$ & $1.46022(1.65)$ & $0.07209(0.73)$ & $880 \pm 13$ & 12 \\
\hline GC1-10 & Núcleo & 689 & 95 & 0.14 & 0.142 & $0.15642(1.34)$ & $1.55321(1.54)$ & $0.07202(0.75)$ & $935 \pm 12$ & 5 \\
\hline GC1-16 & Núcleo & 407 & 21 & 0.05 & 0.175 & $0.16282(1.70)$ & $1.62842(1.87)$ & $0.07253(0.77)$ & $971 \pm 16$ & 3 \\
\hline GC1-14 & Núcleo & 1339 & 161 & 0.12 & -0.106 & $0.20940(1.41)$ & $2.31863(1.56)$ & $0.08031(0.66)$ & $1227 \pm 17$ & -2 \\
\hline
\end{tabular}

${ }^{\mathrm{a}}$ Los análisis fueron hechos por Alexander Iriondo usando SHRIMP-RG instalada en la Universidad de Stanford, California, en copropiedad con el Servicio Geológico de Estados Unidos. El procedimiento SHRIMP usado fue similar al reportado por Williams (1998), y los datos isotópicos fueron graficados por medio de los programas IsoplotEx y Squid de Ludwing (2001a,b). El rayo iónico primario de oxígeno operó a 2-4 nA y excavó un área de 25-30 $\mu \mathrm{m}$ de diámetro a una profundidad de $c a .1 \mu \mathrm{m}$, con un rango de sensibilidad de 5 a $30 \mathrm{cps} / \mathrm{ppm} \mathrm{de} \mathrm{Pb}{ }^{\mathrm{b}}{ }^{\mathrm{Pb}}$ común. El análisis de las muestras y del patrón de circón usado, R33 de $419 \mathrm{Ma}$, fueron alternados para una control más estrecho de la relación $\mathrm{Pb} / \mathrm{U}$. Las concentraciones de $\mathrm{U}$ y $\mathrm{Pb}$ tienen un $10-20 \%$ de incertidumbre. ${ }^{\mathrm{c}}$ Relaciones atómicas corregidas por $\mathrm{Pb}$ inicial usando la cantidad de ${ }^{204} \mathrm{~Pb}$ y el promedio correspondiente al valor de la Tierra de Stacey y Kramers (1975). Las relaciones ${ }^{206} \mathrm{~Pb} / 238 \mathrm{U}$ fueron normalizadas al patrón de circón R33. ${ }^{\mathrm{d}}$ Los errores en $2 \sigma$ son presentados en paréntesis en \%. ${ }^{\mathrm{e}}$ Errores absolutos presentados en el nivel de $1 \sigma$ en Ma. ${ }^{\mathrm{f}}$ El grado de discordancia corresponde al porcentaje de la distancia desde el punto de análisis hasta la intersección con la concordia (equivalente a su edad ${ }^{207} \mathrm{~Pb} /{ }^{206} \mathrm{~Pb}$ ) a lo largo de una línea recta extrapolada hasta el punto de origen a $0 \mathrm{Ma}$.

edad de intersección superior de $1105 \pm 80 \mathrm{Ma}$. La edad concordante del Pérmico temprano es considerada la edad de la migmatización en la falla de Caltepec, y la edad de intersección superior del Mesoproterozoico, similar a la obtenida en el granito Cozahuico, sugiere también que los gneises del Complejo Oaxaqueño pueden ser los protolitos $\mathrm{y} / \mathrm{o}$ fuentes de componentes heredados. Dado que las relaciones geológicas indican que la migmatización, con fusión parcial de gneises proterozoicos, y el emplazamiento del granito Cozahuico y su deformación dúctil, fueron fenómenos más o menos simultáneos relacionados con la colisión oblicua de los complejos cristalinos Acatlán y Oaxaqueño, las edades del plutón, de la deformación dúctil a lo largo de la falla de Caltepec, y del evento de colisión fueron consideradas, por lo tanto, del Pérmico temprano (Elías-Herrera y Ortega-Gutiérrez, 2000, 2002). Datos geocronológicos más recientes, dados a conocer por primera vez aquí, vienen a fortalecer esta interpretación.

Debido a que la edad del granito Cozahuico no quedó determinada por medio del método geocronológico convencional de U-Pb, la misma muestra de este plutón (GC1) fue analizada con microsonda iónica sensitiva de alta resolución (SHRIMP, por sus siglas en inglés). Por este método, la edad del granito Cozahuico quedó claramente establecida en $270.4 \pm 2.6$ Ma y componentes heredados del Mesoproterozoico en el plutón son confirmados. Los cristales de circones analizados fueron seleccionados manualmente a partir de los concentrados de minerales pesados no magnéticos, y montados posteriormente en resina epóxica para ser desbastados a la mitad de su espesor y pulidos. Se hicieron 20 puntos de análisis en circones cuyas edades ${ }^{206} \mathrm{~Pb} /{ }^{238} \mathrm{U}$ se muestran en la Tabla 2 , y los diagramas concordia correspondientes se presentan en la Figura $7 \mathrm{c}$ y $7 \mathrm{~d}$. De estas edades 13 son concordantes o casi concordantes y corresponden a análisis puntuales en los bordes de cristales zonificados de circón (Figura 8). Las siete edades restantes son ligeramente discordantes y representan puntos de análisis en los núcleos antiguos de los granos de circones (Figura 8). Las edades concordantes varían desde $257 \pm 4$ Ma hasta $286 \pm 4 \mathrm{Ma}$, con una edad concordante promedio de $270.4 \pm 2.6 \mathrm{Ma}$ (Figura $7 \mathrm{c} \mathrm{y} \mathrm{d}$ ) que corresponde claramente a la edad de cristalización del granito Cozahuico. Es importante señalar que de las edades discordantes, las menos discordantes, $971 \pm 16$ Ma (3\% discordante) y $1227 \pm 17 \mathrm{Ma}$ (-2\% discordante), corresponden a núcleos o granos de circones heredados y son comparables a las de rocas granulíticas y metaígneas de la porción norte del Complejo Oaxaqueño (Solari et 
al., 2003; Keppie et al., 2003). Adicionalmente, cabe mencionar que la mayoría de estas edades discordantes tienen un arreglo lineal cuya intersección superior define una edad de $\sim 1000 \mathrm{Ma}$ (Figura 7c), la cual también coincide con la edad del metamorfismo granulítico del Complejo Oaxaqueño.

La edad de cristalización del granito Cozahuico de 270.4 \pm 2.6 Ma resultó ser ligeramente más joven, incluso dentro de los rangos de error, que la edad de 275.6 \pm 1 Ma para el leucosoma granítico en las migmatitas. Sin embargo, y al margen de la duda razonable en la diferencia de edades por el hecho de que los datos U-Pb corresponden a análisis de laboratorios y geocronología de circones diferentes, ambas edades pérmicas se consideran relacionadas al mismo fenómeno sintectónico de deformación, metamorfismo, migmatización, fusión parcial y magmatismo ocurrido en la zona de falla de Caltepec, producto de la colisión transpresiva entre los complejos metamórficos Acatlán y Oaxaqueño. El granito Cozahuico, al menos en su porción norte que es la parte fechada, puede entonces representar fases tardías de este evento tectonomagmático. La edad de las migmatitas y del granito Cozahuico en la zona de contacto entre los complejos cristalinos es congruente con la edad leonardiana (Weber, 1997) de la Formación Matzitzi como unidad de traslape en el área de Metzontla. Además, la relación discordante entre milonitas de la falla de Caltepec y la Formación Matzitzi, aunque plegada pero sin deformación cristaloplástica, implica un tasa de exhumación muy rápida de la zona de cizalla dúctil, lo cual es consistente con la coexistencia de foliaciones magmática y de estado sólido (e.g., Miller y Paterson, 1994) en el granito Cozahuico, y la preservación como fase metaestable de epidota magmática (e.g., Drummond et al., 1997) tanto en el granito como en los neosomas graníticos.
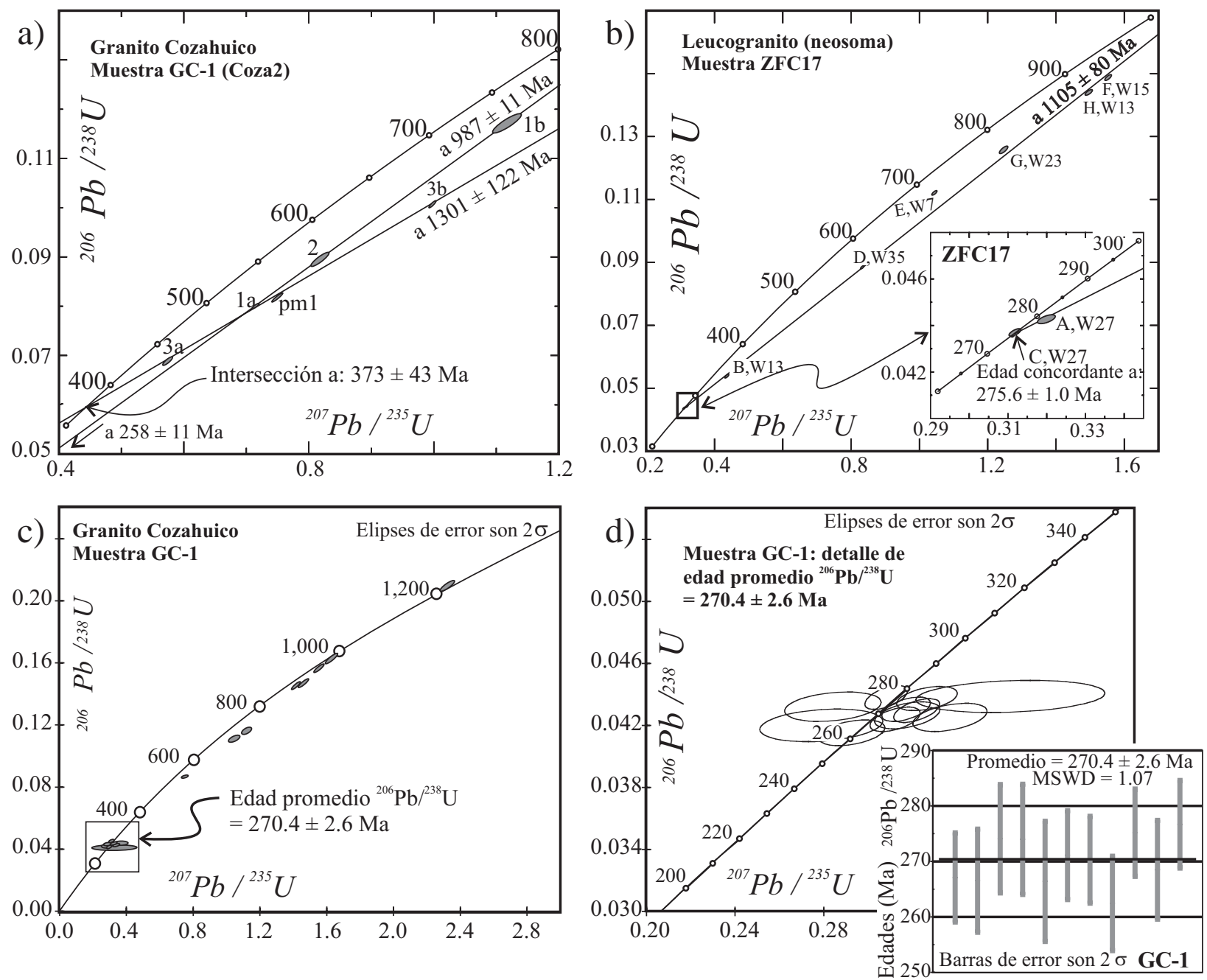

Figura 7. Diagramas concordia para: (a) fracciones discordantes diferentes de circones del granito Cozahuico (muestra GC-1); (b) para fracciones discordantes diferentes de circones de leucosoma granítico (muestra ZFC17) en gneises migmatíticos; en este caso la fracción concordante, C,W27, a $275.6 \pm 1$ Ma define la edad de la migmatización en la zona de falla de Caltepec; (c) para análisis puntuales por SHRIMP en granos diferentes de circones de la misma muestra del granito Cozahuico (GC-1), con detalle en los análisis puntuales concordantes que sustentan una edad promedio ${ }^{206} \mathrm{~Pb} /{ }^{238} \mathrm{U}$ de $270.4 \pm 2.6 \mathrm{Ma}$ (d). Los datos en los diagramas (a) y (b), y (c) y (d), corresponden a los de las Tablas 1 y 2, respectivamente. 


\section{Circones del granito Cozahuico (GC-1)}

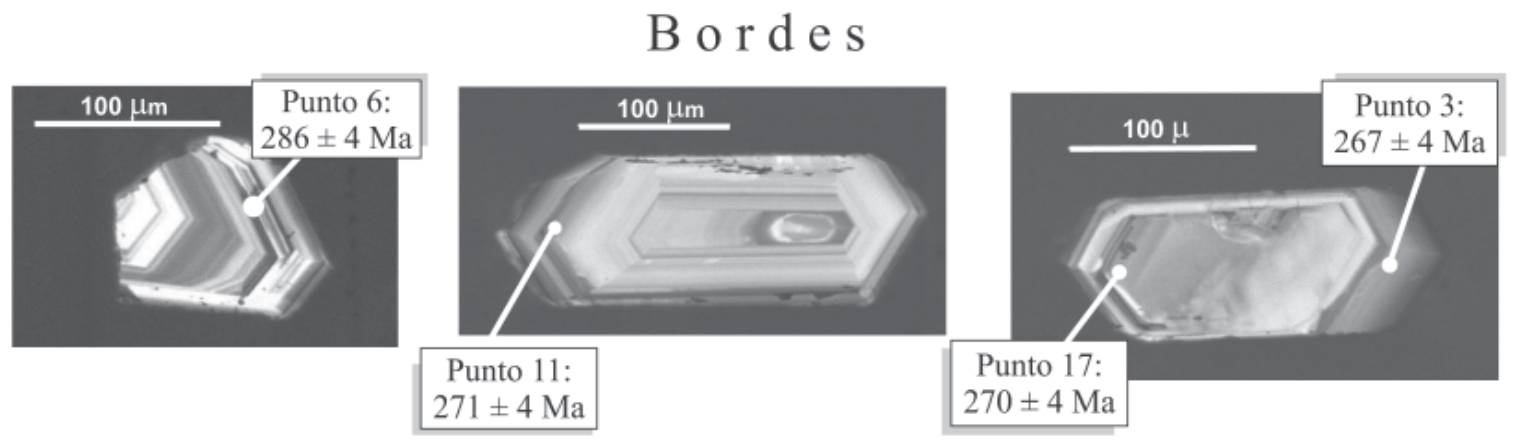

\section{$\mathrm{N}$ ú c l e o s}
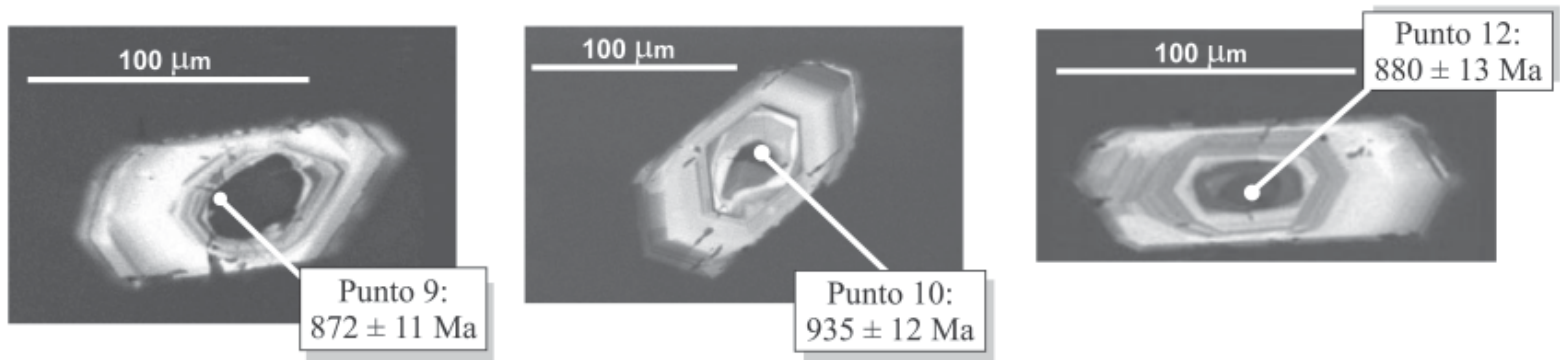

Figura 8. Cristales de circones del granito Cozahuico (muestra GC-1). Las fotomicrografías fuero tomadas con catodoluminiscencia para resaltar y señalar el zoneamiento interno de los granos y algunos de los puntos de análisis geocronológico con microsonada iónica sensitiva de alta resolución (SHRIMP, por sus siglas en inglés). Los resultados completos de estos análisis de presentan en la Tabla 2.

Datos termocronológicos de ${ }^{40} \mathrm{Ar} /{ }^{39} \mathrm{Ar}$ corroboran también el modelo de exhumación rápida.

\subsection{Datos ${ }^{40} \mathrm{Ar} /{ }^{39} \mathrm{Ar}$}

Los datos de geocronología ${ }^{40} \mathrm{Ar} /{ }^{39} \mathrm{Ar}$ y detalles del procedimiento analítico, así como los espectros de edades aparentes correspondientes, se presentan en la Tabla 3 y en la Figura 9, respectivamente. Para el propósito de este estudio, una edad de meseta es obtenida cuando las edades aparentes de al menos tres segmentos o pasos consecutivos comprenden un mínimo de $55 \%$ del ${ }^{39} \mathrm{Ar}_{\mathrm{k}}$ liberado y son consistentes, dentro del error $2 \sigma$, con la edad integrada de los segmentos de meseta. Los errores presentados en la Tabla 3 y los espectros de edades de la Figura 9, así como en los diagramas de correlación isotópica (no incluidos) representan la precisión analítica en $\pm 2 \sigma$. Los datos completos ${ }^{40} \mathrm{Ar} /{ }^{39} \mathrm{Ar}$ están disponibles con el primer autor. La muestra SST4 (hornblenda) corresponde a una banda de melanosoma anfibolítico alternada con bandas de leucosoma granítico de gneises migmatíticos encajonados en el granito Cozahuico. Los gneises migmatíticos están en el bloque del alto de una falla inversa sobre esquistos de mica milonitizados del Complejo Acatlán en la barranca Agua Salada. La muestra SST3 (mica blanca) corresponde precisamente al esquisto de mica ubicado en el bloque del bajo. La localización de ambas muestras se señala en la Figura 3.

La edad de meseta de $278.06 \pm 1.32$ Ma para la hornblenda (muestra SST4) de los gneises anfibolíticos, en principio, pudiera interpretarse como una edad de enfriamiento de las migmatitas en la zona de falla, y estaría marcando el tiempo en que la roca pasó la isoterma de $530 \pm 40^{\circ} \mathrm{C}$ (temperatura de cierre para la retención de $\mathrm{Ar}$ radiogénico en hornblenda; Harrison, 1981). Sin embargo, la parte granítica leucosomática dió una edad U- $\mathrm{Pb}$ (circón) concordante de $275.6 \pm 1 \mathrm{Ma}$ (Figuras $6 \mathrm{~h}$ y $7 \mathrm{~b}$ ) que fecha la anatéxis, por lo que la edad ${ }^{40} \mathrm{Ar} /{ }^{39} \mathrm{Ar}$ de la hornblenda, ligeramente mayor que la edad concordante $\mathrm{U}-\mathrm{Pb}$ del circón en el leucosoma adyacente, puede estar reflejando más bien exceso de ${ }^{40} \mathrm{Ar}$ distribuido uniformemente en la estructura del anfíbol. La hornblenda del melanosoma anfibolítico, como porción restítica de las migmatitas, probablemente absorbió ${ }^{40} \mathrm{Ar}$ radiogénico liberado por difusión de otras fases minerales, debido a que la migmatización y el emplazamiento del granito Cozahuico en la zona de falla probablemente reflejan una evolución isotérmica sintectónica de alta temperatura $\left(\sim 700^{\circ} \mathrm{C}\right) \mathrm{de}$ $\sim 6 \mathrm{Ma}$ de duración relacionada con el evento de colisión transpresiva.

Respecto a la edad de meseta ${ }^{40} \mathrm{Ar} /{ }^{39} \mathrm{Ar}$ de $268.59 \pm 1.27$ Ma de la mica blanca del esquisto de mica milonitizado (muestra SST3) (Figura 9), ésta puede considerarse una 
edad de enfriamiento metamórfico a $350-400^{\circ} \mathrm{C}$ (rango de temperatura de cierre para la moscovita en el sistema isotópico ${ }^{40} \mathrm{Ar} /{ }^{39} \mathrm{Ar}$; Wijbrans y McDougall, 1986; Hames y Bowring, 1994). La edad ${ }^{40} \mathrm{Ar}{ }^{39} \mathrm{Ar}$ es ligeramente más joven que la edad U-Pb (circón) de $270.4 \pm 2.6 \mathrm{Ma}$ del granito Cozahuico, por lo que implicaría un enfriamiento muy rápido de $\sim 180^{\circ} \mathrm{C} / \mathrm{Ma}$ (Figura 10) tomando en consideración la pequeña diferencia de edades entre el granito y la roca metamórfica. Debido a que el esquisto de mica milonitizado representa el bloque del bajo justamente en el borde occidental de la zona de falla de Caltepec, la edad de la mica está fechando una etapa de enfriamiento del cabalgamiento dúctil del granito Cozahuico y los megaxenolitos de gneises migmatíticos sobre el Complejo Acatlán. La edad ${ }^{40} \mathrm{Ar} /{ }^{39} \mathrm{Ar}$ de la hornblenda (probable exceso de ${ }^{40} \mathrm{Ar}$ ) en los gneises migmatíticos, que representan el bloque del alto en las localidades muestreadas, es inconsistente con una historia de enfriamiento simple al considerar la edad ${ }^{40} \mathrm{Ar} /{ }^{39} \mathrm{Ar}$ de la mica (Figura 10 ).

En conjunto, los datos U-Pb y ${ }^{40} \mathrm{Ar} /{ }^{39} \mathrm{Ar}$ sugieren un enfriamiento rápido, consistente con una tasa de exhumación muy alta. El levantamiento rápido del Complejo Oaxaqueño relacionado con el evento de transpresión quedó también registrado estratigráfícamente en la Formación Matzitzi. La porción basal de esta formación en el área de Coatepec, $5 \mathrm{~km}$ al oriente de la zona de falla de Caltepec, se caracteriza por centenares de metros de conglomerados con cantos redondeados de gneises proterozoicos de varios metros de diámetro indicando depósitos catastróficos de muy alta energía relacionados a relieves topográficos muy abruptos e inestables.

\section{Isotopía de Rb-Sr y Sm-Nd de migmatitas y del granito Cozahuico}

En la Tabla 4 se presentan datos isotópicos $\mathrm{Rb}-\mathrm{Sr}$ y $\mathrm{Sm}-\mathrm{Nd}$ de los gneises migmatíticos bandeados y del granito Cozahuico. Los detalles resumidos del procedimiento analítico usado también se incluyen en esta Tabla. Las muestras de gneises migmatíticos analizadas corresponden a bandas alternadas de melanosoma anfibolítico y leucosoma granítico colectadas en la misma localidad de la muestra ZFC17, fechada por U-Pb (circón) en 275.6 \pm 1 Ma (Figuras 3 y 6h). Debido a que esta fecha es la edad de la migmatización, las relaciones isotópicas iniciales fueron calculadas a $275 \mathrm{Ma}$. Las edades modelo Sm-Nd $\left(\mathrm{T}_{\mathrm{DM}}\right)$ corresponden al modelo evolutivo de manto empobrecido de DePaolo (1981). Las bandas de melanosoma y leucosoma tienen una relación inicial ${ }^{87} \mathrm{Sr}{ }^{166} \mathrm{Sr}$ de 0.70616 a 0.70686 , y valores iniciales negativos $\varepsilon \mathrm{Nd}_{(\mathrm{i})}$ que varían desde -2.7 hasta -5.8 , con edades $\mathrm{T}_{\mathrm{DM}}$ de 1.2 a $1.6 \mathrm{Ga}$. El granito Cozahuico se caracteriza por una relación inicial ${ }^{87} \mathrm{Sr} /{ }^{86} \mathrm{Sr}$ más baja que 0.70435-0.70560, un $\varepsilon \mathrm{Nd}_{(\mathrm{i})}$ de -3.2 a -3.6 , y edades $\mathrm{T}_{\mathrm{DM}}$ menos variables de $1.0 \mathrm{Ga}$ a $1.2 \mathrm{Ga}$. Debido posiblemente a un fraccionamiento químico y mineralógico durante la migmatización (e.g., Zeng et al., 2005), las relaciones ${ }^{147} \mathrm{Sm} /{ }^{144} \mathrm{Nd}$ de las muestras del melanosoma $(\mathrm{CO} 98 / 58 \mathrm{C} 2$

Tabla 3. Datos ${ }^{40} \mathrm{Ar} /{ }^{39} \mathrm{Ar}$ para dos muestras de la zona de falla de Caltepec ${ }^{\mathrm{a}}$.

\begin{tabular}{|c|c|c|c|c|c|}
\hline $\begin{array}{l}\text { Potencia de láser } \\
\text { (Watts) }\end{array}$ & $\mathrm{Ca} / \mathrm{K}$ & $\begin{array}{c}{ }^{40} \text { Ar atm } \\
(\%)\end{array}$ & $\begin{array}{l}{ }^{39} \mathrm{Ar} \\
(\%)\end{array}$ & ${ }^{40} \mathrm{Ar} * /{ }^{39} \mathrm{Ar}_{\mathrm{K}}$ & $\begin{array}{l}\text { Edad } \\
\text { (Ma) }\end{array}$ \\
\hline \multicolumn{6}{|c|}{$\begin{array}{l}\text { Muestra SST3 (mica blanca, } 15 \mathrm{mg} \text { ), esquisto de mica. Edad integrada: } 268.31 \pm 1.34 \mathrm{Ma} \text {; edad de correlación: } 268.53 \pm 1.19 \mathrm{Ma}(\mathrm{MSWD}=0.892) \text {; } \\
\text { edad de meseta: } 268.59 \pm 1.27 \mathrm{Ma} \text { (mod. err. 0.92; } 95.6 \% \text { de }{ }^{39} \mathrm{Ar} \text { liberado en seis pasos). }\end{array}$} \\
\hline 0.75 & 0.038 & 35.15 & 0.27 & $12.404 \pm 8.962$ & $154.95 \pm 107.27$ \\
\hline 1.50 & 0.025 & 7.78 & 1.26 & $20.042 \pm 1.894$ & $244.13 \pm 21.57$ \\
\hline 2.00 & 0.000 & 0.00 & 2.92 & $23.201 \pm 0.869$ & $279.77 \pm \quad 9.71$ \\
\hline 2.50 & 0.002 & 4.16 & 9.63 & $22.304 \pm 0.281$ & $269.72 \pm \quad 3.16$ \\
\hline 3.00 & 0.000 & 1.75 & 17.55 & $22.062 \pm 0.175$ & $267.00 \pm 1.96$ \\
\hline 4.00 & 0.000 & 0.38 & 25.37 & $22.250 \pm 0.133$ & $269.11 \pm 1.50$ \\
\hline 5.00 & 0.000 & 0.54 & 14.00 & $22.197 \pm 0.216$ & $268.51 \pm \quad 2.43$ \\
\hline 6.00 & 0.001 & 0.07 & 13.25 & $22.290 \pm 0.213$ & $269.56 \pm \quad 2.39$ \\
\hline 7.00 & 0.006 & 0.30 & 15.75 & $22.156 \pm 0.211$ & $268.06 \pm \quad 2.37$ \\
\hline \multicolumn{6}{|c|}{$\begin{array}{l}\text { Muestra SST4 (hornblenda, } 22 \mathrm{mg} \text { ), anfibolita. Edad integrada: } 276.35 \pm 1.50 \mathrm{Ma} \text {; edad de correlación: } 278.73 \pm 2.06 \mathrm{Ma}(\mathrm{MSWD}=2.418) ; \text { edac } \\
\text { de meseta: } 278.06 \pm 1.32 \mathrm{Ma} \text { (mod. err. } 1.61 ; 94.2 \% \text { de }{ }^{39} \text { Ar liberado en cuatro pasos). }\end{array}$} \\
\hline 2.50 & 3.725 & 70.50 & 2.55 & $21.687 \pm 2.434$ & $263.08 \pm 27.48$ \\
\hline 4.00 & 8.969 & 37.11 & 3.28 & $19.385 \pm 1.033$ & $236.91 \pm 11.83$ \\
\hline 5.00 & 11.296 & 25.29 & 1.96 & $22.057 \pm 1.359$ & $267.25 \pm 15.30$ \\
\hline 6.00 & 2.435 & 8.00 & 12.33 & $23.136 \pm 0.296$ & $279.36 \pm 3.32$ \\
\hline 6.50 & 12.854 & 2.25 & 41.45 & $22.898 \pm 0.144$ & $276.70 \pm 1.61$ \\
\hline 7.00 & 12.865 & 0.96 & 15.16 & $23.181 \pm 0.247$ & $279.86 \pm 2.76$ \\
\hline 7.50 & 12.707 & 1.60 & 23.27 & $23.152 \pm 0.158$ & $279.54 \pm 1.77$ \\
\hline
\end{tabular}

${ }^{a}$ Los minerales estudiados fueron concentrados y limpiados por técnicas normales de molienda, lavado, y selección y separación manual con microscopio binocular a partir de fracciones de 40-60 mallas en el laboratorio de separación de minerales del Instituto de Geología de la UNAM. Los minerales separados fueron cargados en paquetes de papel-aluminio e irradiados en el reactor nuclear McMaster (Hamilton, Ontario). Los análisis ${ }^{40} \mathrm{Ar} /{ }^{39} \mathrm{Ar}$ fueron hechos por Amabel Ortega en el laboratorio de geocronología de Queen's University, Kingston, Ontario, Canadá, por medio de la técnica de calentamiento a pasos con láser descrita por Clark et al. (1998). Los datos fueron corregidos por blancos, discriminación de masa e interferencias de neutrón inducido. 

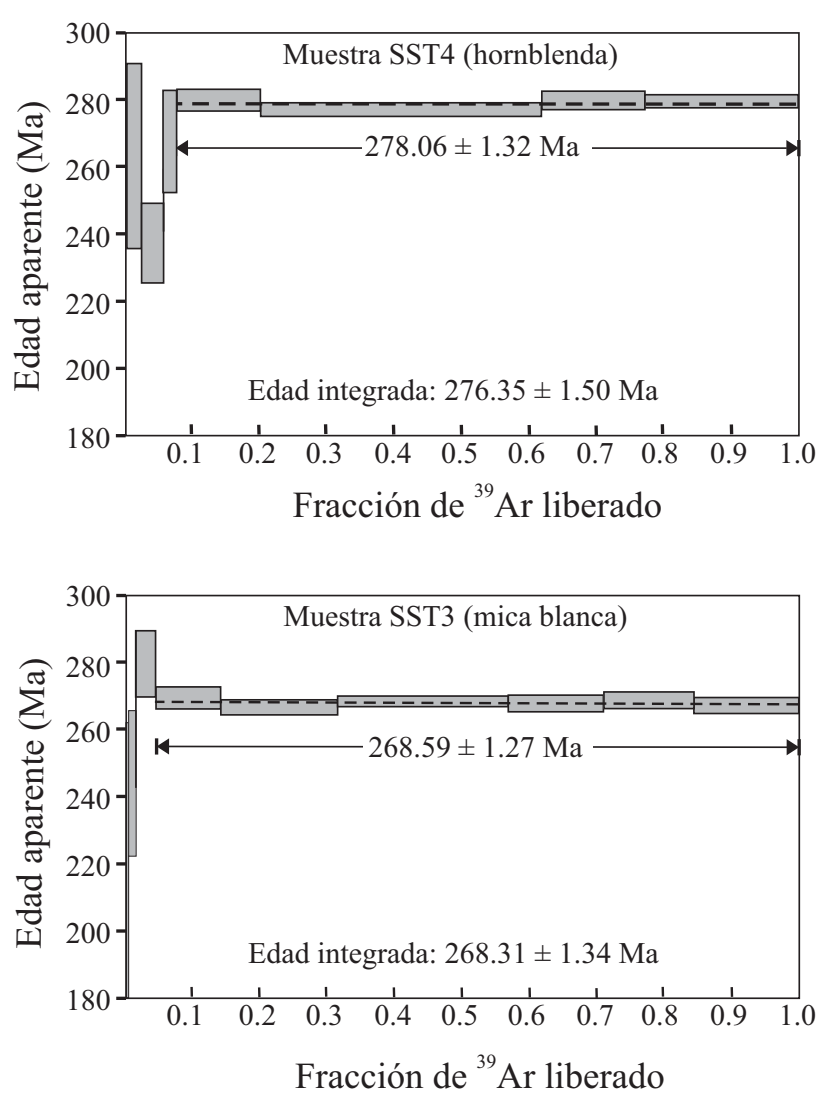

Figura 9. Espectros de edades aparentes a partir de datos ${ }^{40} \mathrm{Ar} /{ }^{39} \mathrm{Ar}$ (Tabla 3) por calentamiento a pasos de hornblenda (muestra SST4) y mica blanca (muestra SST3) de anfibolita y esquisto de mica, respectivamente, de la zona de falla de Caltepec.

y CO98/58B) y una del leucosoma (CO98/58C1) son relativamente altas $(>0.16)$ lo que resulta en edades modelo anormales $(>2.0 \mathrm{Ga})$. En estos casos las edades modelo fueron corregidas por fraccionamiento (Milisenda et al., 1994) a $275 \mathrm{Ma}$.

Las relaciones iniciales de ${ }^{87} \mathrm{Sr} /{ }^{86} \mathrm{Sr} \leq 0.70686$ de los gneises migmatíticos y del granito Cozahuico sugieren que en el evento de fusión parcial y magmatismo sintectónico dentro de la zona de falla de Caltepec el material involucrado fue poco evolucionado, o corresponde a un material fuente poco diferenciado de la corteza inferior. Los datos Rb-Sr son, sin embargo, inconsistentes con los datos Sm-Nd que indican material cortical evolucionado. La relación $\mathrm{Rb} / \mathrm{Sr}$, que influye mucho en el cálculo de la relación inicial ${ }^{87} \mathrm{Sr} /{ }^{86} \mathrm{Sr}$, es muy baja en los gneises y en el granito. Por ejemplo, el leucosoma granítico y el granito Cozahuico, con valores negativos de $\varepsilon \mathrm{Nd}_{(\mathrm{i})}$ de -3.16 a -4.96, tienen relaciones $\mathrm{Rb} / \mathrm{Sr}$ que varían de 0.01 a 0.28 ; mientras que granitos alleghanianos (de $\sim 300 \mathrm{Ma})$ de los Apalaches meridionales, con valores iniciales $\varepsilon \mathrm{Nd}_{(300 \mathrm{Ma})}$ negativos comparables, tienen relaciones $\mathrm{Rb} / \mathrm{Sr}$ de 0.12 a 1.24 , con relaciones iniciales ${ }^{87} \mathrm{Sr} /{ }^{86} \mathrm{Sr}$ de $0.70642-0.70915$ (Sampson et al., 1995). Es probable, por lo tanto, que en las rocas de la zona de falla de Caltepec haya ocurrido cierta removilización de $\mathrm{Rb}$, y que el sistema $\mathrm{Rb}-\mathrm{Sr}$ no permaneció completamente cerrado durante la historia de retrabajo de la falla. Los datos $\mathrm{Rb}-\mathrm{Sr}$ y Sm-Nd, no obstante, reflejan claramente involucramiento significativo de corteza proterozoica en la generación del granito Cozahuico.

De acuerdo con las correlaciones geológicas locales, se ha interpretado que los gneises bandeados encajonados en el granito Cozahuico corresponden a gneises proterozoicos del Complejo Oaxaqueño completamente rehomogeneizados por migmatización y fusión parcial en el Pérmico temprano, evento tectonotérmico relacionado también con la generación del granito. Las edades $\mathrm{T}_{\mathrm{DM}}$ de 1.36, 1.48 y $1.62 \mathrm{Ga}$ del leucosoma granítico que coinciden con las edades modelo del Complejo Oaxaqueño (1.47 - $1.60 \mathrm{Ga}$; Ruiz et al., 1988a) son congruentes con esta interpretación. Sin embargo, los valores $\varepsilon \mathrm{Nd}_{(\mathrm{i})}$ tanto de los gneises migmatíticos como del granito Cozahuico (Tabla 4) no son consistentes con las características isotópicas del Complejo Oaxaqueño para el Pérmico temprano (Figura 11). Los valores estimados de $\varepsilon \mathrm{Nd}_{(275 \mathrm{Ma})}$ para el Complejo Oaxaqueño varían de -6.5 a -10.2 según los datos $\mathrm{Sm}-\mathrm{Nd}$ de Ruiz et al. (1988a). Aunque se hicieron correcciones por fraccionamiento de $\mathrm{Sm} / \mathrm{Nd}$ durante el evento de migmatización-fusión parcial, las características isotópicas de los gneises migmatíticos y del granito Cozahuico, con edades variables $\mathrm{T}_{\mathrm{DM}}$ de $\sim 1.0 \mathrm{Ga}$ a $\sim 1.6 \mathrm{Ga}$, no pueden explicarse únicamente por medio de fusión parcial de los gneises del Complejo Oaxaqueño.

Con los datos isotópicos disponibles, el granito Cozahuico puede considerarse más bien como producto de fusión de corteza proterozoica y componentes de manto empobrecido o corteza inferior poco diferenciada. Los núcleos de circones con edades proterozoicas $\mathrm{U}-\mathrm{Pb}$ en el granito es una evidencia directa del involucramiento del Complejo Oaxaqueño en la generación del plutón, lo cual es consistente con los valores negativos de $\varepsilon \mathrm{Nd}_{(\mathrm{i})}$ indicando material cortical antiguo como fuente. Por otro lado, la baja relación inicial ${ }^{87} \mathrm{Sr} /{ }^{86} \mathrm{Sr}$ de $0.70435-0.70560$ para el granito, no obstante la pérdida probable de $\mathrm{Rb}$ en el plutón, puede reflejar la componente de material juvenil o poco evolucionado. El Complejo Oaxaqueño, como componente cortical involucrado, se caracteriza por relaciones relativamente altas de $\mathrm{Rb} / \mathrm{Sr}$ (Ruiz et al., 1988b). Las edades modelo del granito, con poca variación alrededor de $1.0 \mathrm{Ga}$, pueden, por consiguiente, no tener significado geológico, y representar un valor intermedio entre la edad proterozoica de corteza continental y material de manto paleozoico involucrado. Si esta interpretación es correcta, el manto seguramente tuvo un papel importante, no sólo como elemento activo en la petrogénesis del granito Cozahuico, sino también como fuente de calor en el evento tectonotérmico relacionado con la yuxtaposición de los complejos cristalinos. Xenolitos de rocas máficas, a escala centimétrica, en algunas localidades dentro del granito Cozahuico sugieren tenuemente la presencia de magmas del 
manto durante el proceso. En los Apalaches meridionales, los granitos alleghanianos en el cinturón Inner Piedmont y en el terreno Carolina, pueden representar casos similares al del granito Cozahuico. Muchos de estos plutones son sintectónicos ligados a fallas inversas importantes, sus relaciones isotópica $\mathrm{Sm}-\mathrm{Nd}$, que son comparables a las del Cozahuico, indican esencialmente una formación por anatexis de corteza evolucionada tipo grenvilliana, y se consideran plutones de colisión y no granitos de arco magmático (Sampson et al., 1995).

Respecto a los gneises migmatíticos, isotópicamente no parecen corresponder a la evolución del Complejo Oaxaqueño (Figura 11), a pesar de que los datos U-Pb (circón) del neosoma granítico sugieren claramente componentes heredados procedentes de rocas grenvillianas. Esta apreciación puede ser aparente y solamente estar reflejando la escasez de datos isotópicos $\mathrm{Sm}-\mathrm{Nd}$ del Complejo Oaxaqueño con relación a su extensión y variaciones litológicas. La evolución isotópica del complejo en la Figura 11 corresponde a sólo ocho muestras de la región de Oaxaca. Por otro lado, los gneises migmatíticos de Caltepec muestran buena concordancia con la evolución isotópica $\mathrm{Sm}-\mathrm{Nd}$ del complejo Guichicovi (Weber y Kohler, 1999), y con los gneises Huiznopala y Novillo (Ruiz et al., 1988a) en Hidalgo y Tamaulipas, respectivamente; unidades que, conjuntamente con el Complejo Oaxaqueño, conforman el microcontinente Oaxaquia (OrtegaGutiérrez et al., 1995). Los gneises migmatíticos, por lo anterior, corresponden a bloques de este microcontiente y pueden representar fragmentos del Complejo Oxaqueño rehomogeneizados en facies de anfibolita y transportados a niveles de la corteza media por el granito Cozahuico a lo largo de la falla de Caltepec.

\section{Implicaciones regionales}

La falla de Caltepec, contacto tectónico incuestionable entre los complejos cristalinos más importantes del sur de México, refleja indudablemente los movimientos de convergencia que terminaron configurando Pangea en su porción centro-occidental. El evento tectonomagmático del Pérmico temprano en la falla de Caltepec coincidó con la extinción del arco volcánico Misisípico-Pérmico Las Delicias debido a la colisión del terreno Coahuila de origen gondwánico, contra el margen meridional de Laurencia, y con los últimos pulsos compresivos de la orogenia Marathon-Ouachita (Ross, 1986; López, 1997; Carpenter, 1997).

La falla de Caltepec, a pesar de que sólo aflora en una longitud de $\sim 20 \mathrm{~km}$, debe tener continuidad regional al norte hasta su truncamiento con la Faja Volcánica Transmexicana y hacia el sur hasta su terminación abrupta en el Complejo Xolapa, basamento del terreno Chatino. La falla representa un límite de terrenos con un grado elevado de aloctonía dado el registro geológico tan diferente en los terrenos que delimita. En el ánalisis regional de este límite tectónico hay interrogantes fundamentales tales como: ¿Por qué la suturación entre los bloques continentales es directa, sin que haya aparentemente elementos oceánicos entre ellos? ¿Se trata de una sutura críptica en la que estos elementos fueron eliminados por erosión? ¿Cuánto movimiento representa la zona de falla en su deformación dúctil? Con los datos actuales sólo se pueden abordar parcialmente estos cuestionamientos, aunque con estudios posteriores se pueden ofrecer respuestas más concluyentes.

La prolongación hacia el sur de la falla de Caltepec está claramente confirmada en el área de Tlapiltepec-Tejuapan, al menos en su reactivación neogénica como se discute más adelante. En el área de Cuanana (Figura 1), 150 $\mathrm{km}$ al sur de Caltepec, sobre la prolongación meridional de la falla, aflora un plutón gabróico-diorítico cubierto discordantemente por areniscas y limolitas con flora fósil del Jurásico Medio. El plutón de Cuanana, con datos previos K-Ar de $260 \pm 20 \mathrm{Ma}$ (hornblenda; Grajales-Nishimura et al., 1986), presenta zonas miloníticas norte-sur, con sentido de cizalla derecha (Vega-Carrillo et al., 1998) consistente con la deformación dúctil de la falla de Caltepec. Datos recientes de U-Pb (SHRIMP, circones) de $307 \pm 2 \mathrm{Ma}$ (Pensilvánico Medio) para el plutón de Cuanana (Elías-

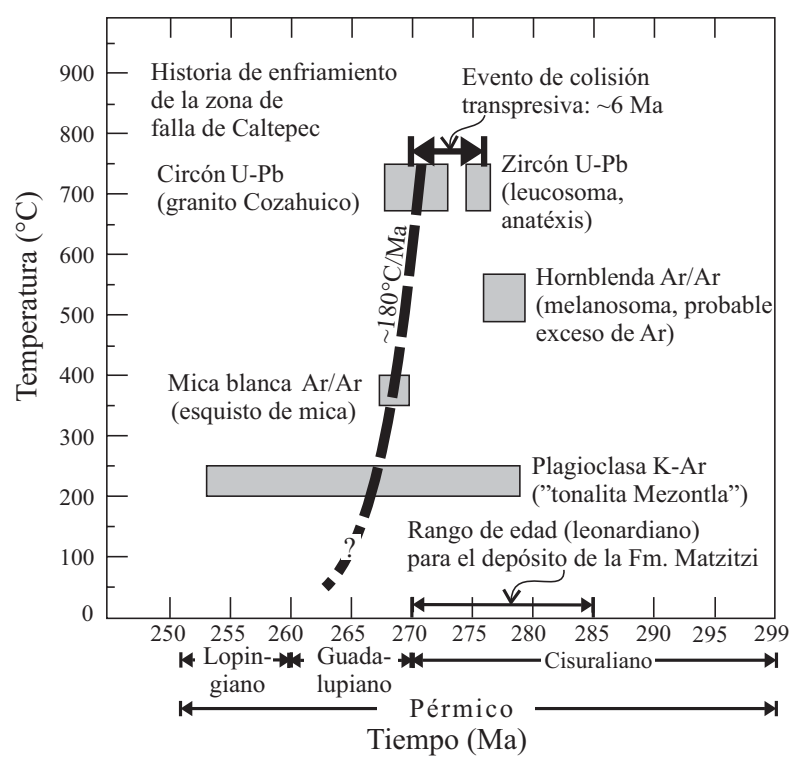

Figura 10. Historia preliminar de enfriamiento de la zona de falla de Caltepec. Los rectángulos representan los rangos de errores en los datos geocronológicos y en las temperaturas para la ocurrencia de fusión parcial y magmatismo en la zona de falla, y temperaturas de cierre para retención de ${ }^{40} \mathrm{Ar}$ radiogénico $\left(530 \pm 40^{\circ} \mathrm{C}\right.$ para la hornblenda, Harrison, 1981 ; $350-400^{\circ} \mathrm{C}$ para la moscovita, Wijbrans y McDougall, 1986; Hames y Bowring, $1994 ; 200-250^{\circ} \mathrm{C}$ para la plagioclasa, McDougall y Harrison, 1988). Los datos K-Ar de la "tonalita Metzontla" del área de Los Reyes Metzontla son de Torres-Vargas et al. (1986). La división del Pérmico es de acuerdo con Gradstein et al. (2004), y la edad leonardiana señalada corresponde a las edades Artinskiano y Kunguriano de estos mismos autores. Para su discusión ver el texto. 
Tabla 4. Datos isotópicos Rb-Sr y Sm-Nd de gneises migmatíticos bandeados y del granito Cozahuico en la zona de falla de Caltepec ${ }^{\mathrm{a}}$.

\begin{tabular}{|c|c|c|c|c|c|c|c|c|c|c|c|c|c|}
\hline Muestra & Litología & $\begin{array}{c}\mathbf{R b} \\
(\mathbf{p p m})\end{array}$ & $\underset{(\mathbf{p p m})}{\mathrm{Sr}}$ & ${ }^{87} \mathrm{Rb} /{ }^{86} \mathrm{~S}$ & ${ }^{87} \mathrm{Sr} /{ }^{86} \mathrm{Sr} \pm 1 \sigma$ & $\left({ }^{87} \mathrm{Sr} /{ }^{86} \mathrm{Sr}\right) \mathrm{i}^{\mathrm{d}}$ & $\begin{array}{c}\text { Sm } \\
(\mathbf{p p m})\end{array}$ & $\begin{array}{c}\mathbf{N d} \\
(\mathbf{p p m})\end{array}$ & ${ }^{147} \mathrm{Sm} /{ }^{144} \mathrm{Nd}^{1}$ & ${ }^{143} \mathrm{Nd} /{ }^{144} \mathrm{Nd} \pm 1 \sigma$ & $\varepsilon \mathbf{N d}_{(0)}$ & $\varepsilon \mathbf{N d}_{(\mathrm{i})}{ }^{\mathrm{e}}$ & $\begin{array}{l}T_{\mathrm{DM}}{ }^{\mathrm{f}} \\
(\mathbf{G a})\end{array}$ \\
\hline$\overline{\mathrm{CO} 98 / 58 \mathrm{~A}}$ & $\begin{array}{l}\text { Leucosoma } \\
\text { granítico }\end{array}$ & 66.33 & 317.64 & 0.604 & $0.708522 \pm 28$ & 0.706159 & 0.18 & 0.79 & 0.135 & $0.512273 \pm 16$ & -7.12 & -4.96 & 1.48 \\
\hline CO98/58B & $\begin{array}{l}\text { Melanosoma } \\
\text { anfibolítico }\end{array}$ & 126.47 & 239.04 & 1.532 & $0.712356 \pm 34$ & 0.706362 & 6.29 & 22.85 & 0.166 & $0.512403 \pm 22$ & -4.58 & -3.53 & $1.28^{\mathrm{g}}$ \\
\hline $\mathrm{CO} 98 / 58 \mathrm{C} 1$ & $\begin{array}{l}\text { Banda de } \\
\text { leucosoma }\end{array}$ & 5.60 & 779.76 & 0.021 & $0.706945 \pm 32$ & 0.706863 & 3.01 & 10.97 & 0.166 & $0.512351 \pm 19$ & -5.60 & -4.52 & $1.36^{\mathrm{g}}$ \\
\hline $\mathrm{CO} 98 / 58 \mathrm{C} 2$ & $\begin{array}{l}\text { Banda de } \\
\text { melanosoma }\end{array}$ & 23.55 & 446.63 & 0.153 & $0.707394 \pm 52$ & 0.706796 & 12.96 & 43.95 & 0.178 & $0.512465 \pm 18$ & -3.37 & -2.73 & $1.22^{\mathrm{g}}$ \\
\hline CO98/58D & $\begin{array}{l}\text { Leucosoma } \\
\text { granítico }\end{array}$ & 63.33 & 338.15 & 0.542 & $0.708594 \pm 44$ & 0.706474 & 0.25 & 1.09 & 0.139 & $0.512239 \pm 18$ & -7.78 & -5.78 & 1.62 \\
\hline GC-1 & $\begin{array}{l}\text { Granito } \\
\text { Cozahuico }\end{array}$ & 33.50 & 903.61 & 0.107 & $0.704768 \pm 37$ & 0.704350 & 1.07 & 5.70 & 0.113 & $0.512315 \pm 20$ & -6.30 & -3.40 & 1.10 \\
\hline $\mathrm{GC}-1^{\mathrm{b}}$ & $\begin{array}{l}\text { Granito } \\
\text { Cozahuico }\end{array}$ & & & & & & 0.99 & 5.15 & 0.116 & $0.512318 \pm ?$ & -6.24 & -3.56 & 1.14 \\
\hline RT- $16^{\mathrm{c}}$ & $\begin{array}{l}\text { Granito } \\
\text { "La Compañía" } \\
\text { (Cozahuico) }\end{array}$ & & & & & & 2.74 & 16.75 & 0.099 & $0.512301 \pm ?$ & -6.57 & -3.16 & 1.01 \\
\hline RT-20 & $\begin{array}{l}\text { Granito } \\
\text { Cozahuico }\end{array}$ & & & & & & 0.82 & 4.08 & 0.122 & $0.512331 \pm ?$ & -5.99 & -3.60 & 1.19 \\
\hline $634 W-669 W^{d}$ & $\begin{array}{l}\text { Granito } \\
\text { "Caltepec" } \\
\text { (Cozahuico) }\end{array}$ & 97.56 & 350.33 & 0.668 & $0.7080 \pm ?$ & $0.7056 \pm 4$ & & & & & & & \\
\hline
\end{tabular}

${ }^{a}$ Los análisis de $\mathrm{Sr}, \mathrm{Sm}$, y Nd se realizaron con un espectrómetro de masas con fuente iónica térmica FINNIGAN MAT 262 en el Laboratorio Universitario de Geoquímica Isotópica (LUGIS), Instituto de Geofísica, UNAM. El espectrómetro cuenta con ocho colectores Faraday ajustables y todas las mediciones se hicieron de manera estática. Los análisis de Rb se realizaron con un espectrómetro de masas NBS en el Instituto de Geología, UNAM. Todas las relaciones isotópicas de $\mathrm{Sr}$ y Nd se corrigieron por fraccionamiento de masas via normalización a ${ }^{86} \mathrm{Sr} /{ }^{88} \mathrm{Sr}=0.1194 \mathrm{y}{ }^{146} \mathrm{Nd} /{ }^{144} \mathrm{Nd}$ $=0.7219$, respectivamente. Los valores del LUGIS para los estándares NBS $987(\mathrm{Sr})$ y La Jolla (Nd) son: ${ }^{87} \mathrm{Sr} /{ }^{86} \mathrm{Sr}=0.710233 \pm 16\left( \pm 1 \sigma_{\text {abs }}, \mathrm{n}=179\right)$, $\mathrm{y}{ }^{143} \mathrm{Nd} /{ }^{144} \mathrm{Nd}=0.511882 \pm 22\left( \pm 1 \sigma_{\mathrm{abs}}, \mathrm{n}=81\right)$, respectivamente. Las incertidumbres relativas son ${ }^{87} \mathrm{Rb} /{ }^{86} \mathrm{Sr}= \pm 2 \%, \mathrm{y}{ }^{147} \mathrm{Sm} /{ }^{144} \mathrm{Nd}= \pm 1.5 \%(1 \sigma)$. La reproducibilidad relativa $(1 \sigma)$ de las concentraciones de $\mathrm{Rb}$, Sr, Sm y Nd es de $\pm 4.5 \%, \pm 1.8 \%, \pm 3.2 \%, \pm 2.7 \%$, respectivamente. Los promedios de los blancos analíticos obtenidos en el tiempo de los análisis de las muestras son: $0.26 \mathrm{ng}$ para Rb, $4.3 \mathrm{ng}$ para Sr, $1.8 \mathrm{ng}$ para Sm, y $12.7 \mathrm{ng}$ para Nd. ${ }^{\mathrm{b}}$ Datos de Robert López (Comunicación escrita, 15/oct./1998) de la Universidad de California en Santa Cruz, California. ${ }^{\mathrm{c}}$ Datos reportados por Torres-Vargas et al. (1999). El granito "La Compañía" corresponde al granito Cozahuico en su porción norte. ${ }^{\mathrm{d}}$ Datos reportados por Ruiz-Castellanos (1979). Valores promedio de seis muestras. El granito "Caltepec" corresponde al granito Cozahuico en su porción norte. ${ }^{\mathrm{e}}$ Las relaciones isotópica iniciales ${ }_{(i)}$ fueron calculadas a $275 \mathrm{Ma} .{ }^{\mathrm{f}}$ Las edades modelo corresponden a la evolución de manto empobrecido de DePaolo (1981). ${ }^{\mathrm{g}}$ Edades modelo corregidas por fraccionamiento de acuerdo a la ecuación dada por Milisenda et al. (1994).

Herrera et al., datos no publicados) permiten correlacionar a este plutón como parte del enigmático complejo Juchatengo (Grajales-Nishimura, 1988; Grajales-Nishimura et al., 1999) que se localiza entre los complejos Acatlán y Oaxaqueño e incluye rocas ígneas poco evolucionadas. El complejo Juchatengo ha sido interpretado como un rift continental del Paleozoico superior adyacente al Complejo Oaxaqueño (Grajales-Nishimura et al., 1999). Sin embargo, por su edad del Pensilvánico probable, y su localización entre dos complejos metamórficos, así como por sus características litotectónicas de afinidad oceánica, es factible que la secuencia de Juchatengo, como se había propuesto previamente (Elías-Herrera y Ortega-Gutiérrez, 2002), sea en realidad un remanente de la litósfera oceánica que separaba a los bloques continentales que ahora están yuxtapuestos en la región de Caltepec. Si esta interpretación es correcta, la deformación y el metamorfismo regional en la parte baja de la facies de esquisto verde del complejo Juchatengo debe ser del Pérmico temprano relacionados con la yuxtaposición tectónica de los complejos cristalinos
Acatlán y Oaxaqueño. Infortunadamente la secuencia de Juchatengo en su mayor parte está intrusionada por el batolito de Zaniza (67 \pm 4 Ma, K-Ar; Murillo-Muñetón et al., 1986) que obliteró las relaciones de contacto entre el complejo Juchatengo y rocas premesozoicas circundantes.

Asumiendo que los complejos Acatlán y Oaxaqueño, como porción meridional de Oaxaquia, estuvieron separados antes del Pérmico y que posteriormente colisionaron oblicuamente debido a un fallamiento de desplazamiento lateral derecho (Elías-Herrera y Ortega-Gutiérrez, 2002), la magnitud del desplazamiento, tanto paleogeográfico (precolisión) como el registrado en la falla de Caltepec en el evento de colisión no se puede determinar con precisión debido, en el primer caso, a la falta de estudios paleomagnéticos recientes o de correlación faunística, y en el segundo, debido al magmatismo sintectónico del evento que probablemente impidió un registro completo del movimiento. El desplazamiento paleogeográfico entre los bloques Acatlán y Oaxaquia se puede especulativamente 


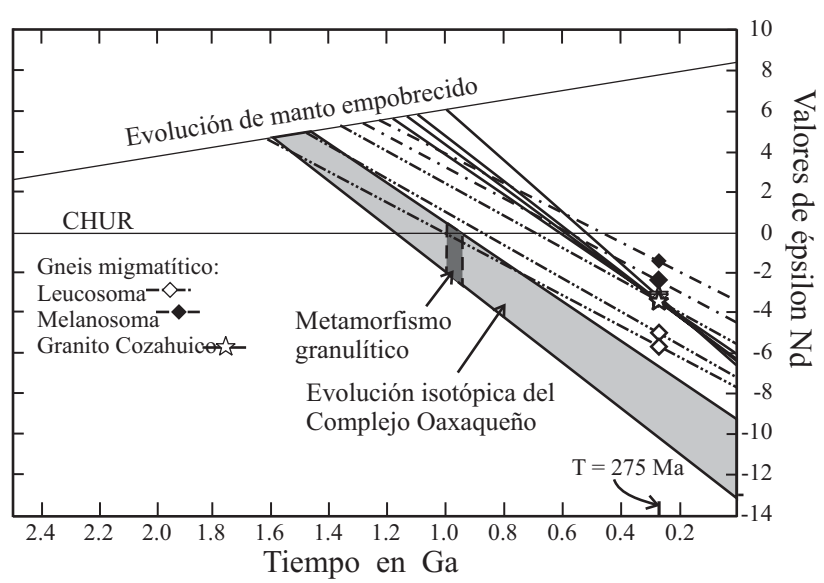

Figura 11. Valores iniciales $\varepsilon \mathrm{Nd}_{(275 \mathrm{Ma})}$ del granito Cozahuico y gneises migmatíticos en la zona de falla de Caltepec con relación a la evolución isotópica Sm-Nd del Complejo Oaxaqueño (Ruiz et al., 1988a). Los valores negativos de $\varepsilon \mathrm{Nd}_{(275 \mathrm{Ma})}$ del granto Cozahuico sugieren que este se formó por anatexis del Complejo Oaxaqueño y una componente de manto empobrecido con un $\varepsilon \mathrm{Nd} \approx+7.5$.

estimar en unos $600 \mathrm{~km}$ si se acepta como razonablemente válida la posición relativa del Complejo Acatlán propuesta por Elías-Herrera y Ortega-Gutiérrez (2002) durante el Misisípico Tardío-Pensilvánico Temprano hasta su yuxtaposición en el Pérmico temprano.

\section{Reactivaciones de la falla de Caltepec}

La falla de Caltepec, de acuerdo con los criterios de reactivación establecidos por Holdsworth et al. (1997), es claramente una estructura longeva polideformada, con deformación dúctil y frágil sobrepuestas, que fue afectada reiteradamente por movimientos tectónicos posteriores a su consolidación en el Pérmico temprano. La deformación posterior en la zona de falla es esencialmente frágil y se manifiesta por fallas de ángulo alto, innumerables fallas menores, cataclasis intensa y brechamiento, lo que implica cambios en la distribución y naturaleza de la deformación. En el fallamiento frágil, los planos de falla y estrías tienen rumbos, orientaciones e inclinaciones diversos, con desarrollos cristalinos fibrosos de cuarzo, clorita, serpentina y epidota en los espejos de falla. Los minerales relacionados con cataclasis son tremolita, sericita, albita, epidota, cuarzo, carbonatos en vetillas, clorita, óxidos de $\mathrm{Fe}-\mathrm{Ti}$, pirita y hematita. El granito Cozahuico en algunos sectores cataclásticos presenta pseudotaquilitas en vetillas y microvetillas. La naturaleza, temporalidad y magnitud de la actividad pos-Pérmico de la falla se desconoce, no obstante, parece ser que las reactivaciones durante el Mesozoico y Cenozoico tuvieron una influencia significativa en el patrón de depósito de secuencias sedimentarias en la región (e.g., López-Ticha, 1985; Meneses-Rocha et al., 1994). Las reactivaciones tectónicas de la zona de falla a lo largo de su historia, a reserva de estudios detallados al respecto, están evidenciadas por criterios estratigráficos, estructurales, geocronológicos y neotectónicos como se menciona enseguida.

\subsection{Reactivaciones mesozoicas}

Durante el Jurásico Medio la falla de Caltepec probablemente tuvo actividad tectónica. Por ejemplo, debido a que el desplazamiento lateral derecho de la Plataforma de Yucatán, relacionada con la abertura del Golfo de México, quedó claramente registrado en la falla de Oaxaca (Alaniz-Álvarez et al., 1996), $50 \mathrm{~km}$ al oriente de la falla de Caltepec, es probable que ésta haya sido reactivada como falla normal o transtensiva. La presencia cercana de capas rojas del Jurásico Medio sobre el Complejo Acatlán en el área de Chazumba, Oaxaca, implica ciertamente actividad tectónica extensional durante esta epoca, pero es dificil discriminar su fuente ya que la inmensa mayoría de los cantos son de cuarzo y cuarcita. Sin embargo, el hecho de que capas rojas jurásicas al parecer no se hayan depositado sobre el Complejo Oxaqueño en el área de la falla de Caltepec indicaría que la cuenca de depósito se ubicó sobre el Complejo Acatlán, y que la falla de Caltepec no tuvo actividad intensa durante el Jurásico, justo cuando la falla de Oaxaca estuvo trabajando y en cuya traza si existen capas rojas del Jurásico (Alzaga-Ruiz, 1991) cubriendo al Complejo Oaxaqueño. La reactivación jurásica de la falla de Caltepec puede ser localmente evaluada en el área de Los Reyes Metzontla por medio del fallamiento que afecta a la Formación Matzitzi. En la prolongación septentrional de la falla en esta área, las edades K-Ar de $167 \pm 8 \mathrm{Ma}$ (biotita) y de $163 \pm 8 \mathrm{Ma}$ (plagioclasa) para "el granito de La Compañía" (granito Cozahuico) y el "dique Los Reyes, intrusivo cataclástico" (Torres-Vargas et al., 1986), respectivamente, pueden corresponder a rehomogeneizaciones isotópicas relacionadas con esta reactivación.

El registro del Jurásico Superior en los bloques al oriente y poniente de la falla de Caltepec es marino y de baja energía, reanudándose las condiciones continentales de energía mucho mayor durante el Cretácico Temprano con el depósito de conglomerados con fragmentos grandes de gneises y esquistos que formaron espesores locales de más de $1000 \mathrm{~m}$ sobre ambos bloques en el área de CaltepecCoatepec. Es interesante señalar que la parte oriental del terreno Zapoteco adyacente a la falla de Oaxaca tiene un registro sedimentológico de carácter pelágico (AlzagaRuiz, 1991) que indicaría para esa época reposo de la falla de Oaxaca, en contraste con lo que ocurría en el área de Caltepec con actividad tectónica y sedimentación clástica continental. Aunque en el área de Tehuacán-Teotitlán, porción septentrional de la falla de Oaxaca (Figura 1), la presencia de migmatitas graníticas de $140.6 \pm 1.5 \mathrm{Ma}$ (U-Pb SHRIMP, circones, Ángeles-Moreno et al., 2004), 
terrígenos marinos del Cretácico Inferior con volcanismo basáltico intercalado, y capas rojas del Cretácico Inferior (?) sugiere una reactivación tectónica compleja de la falla de Oaxaca en esta región. Por lo anterior, parece que durante la historia tectónica mesozoica de la falla de Caltepec, sus movimientos se acoplaron a los de la falla de Oaxaca para acomodar deformación cortical importante en el sur de México.

En la región de Santa María Zaniza, $150 \mathrm{~km}$ al sur del área de Caltepec (Figura 1), el batolito de Zaniza (edad KAr de $67 \pm 4$ Ma, Murillo-Muñetón et al., 1986), tiene una distribución elongada norte-sur que coincide justamente con la prolongación meridional de la zona de falla de Caltepec. Este batolito es de composición granítica en su porción central y granodiorítico a tonalítico hacia sus bordes, e intrusiona predominantemente a la secuencia Juchatengo del Paleozoico tardío, a rocas clásticas del Jurásico Medio, y a rocas calcáreas del Cretácico. Debido a su ubicación y geometría es probable que el emplazamiento del batolito de Zaniza haya estado controlado por el contacto tectónico entre los complejos cristalinos Acatlán y Oaxaqueño, y corresponda a un retrabajo en el Cretácico Tardío de esta zona de debilidad cortical como plutón sellador (stitching pluton) en la región.

\subsection{Reactivaciones cenozoicas}

La tectónica cenozoica asociada a la falla de Caltepec refleja una evolución en la que el terreno Mixteco, al poniente de la falla, parece haber sido el bloque caído durante el Paleógeno, mientras que el terreno Zapoteco, al oriente, parece seguir siendo el bloque levantado durante el Neógeno. La reactivación cenozoica en la falla Caltepec está ejemplificada por la cuña tectónica de conglomerado paleogénico, con grandes clastos de caliza cretácica fosilífera en la zona de falla (Figura 5). El conglomerado está delimitado por fallas normales que afectan la discordancia original y con desplazamientos diferenciales desconocidos que inclinaron $50^{\circ}$ al oriente los estratos gruesos del conglomerado. Aunque en el lado poniente de la cuña tectónica se logró preservar una costra de conglomerado en contacto discordante sobre el granito Cozahuico. El desarrollo y una propagación importante a rumbo de estas fallas frágiles de ángulo alto fueron propiciados en gran medida por la foliación milonítica vertical preexistente en este sector de la zona de falla, evidenciando así cambios en la historia cinemática de estructuras antiguas. El fallamiento normal que disloca a los gneises del Complejo Oaxaqueño (Figura $6 b)$ es también parte de esta reactivación, pero no tienen mucha continuidad a rumbo, lo que contrasta con las fallas nucleadas en la zona milonítica. Se desconoce la temporalidad precisa de las reactivaciones cenozoicas en la región, aunque es probable que éstas hayan sido recurrentes. Un ejemplo de esta recurrencia puede demostrarse por medio de la falla de Santa Lucía, estructura paralela a la falla de Caltepec (Figuras 3 y 12), que pudo haber trabajado simultáneamente con la falla de Caltepec durante el Paleógeno como lo sugieren las relaciones de campo. Sin embargo, la falla de Santa Lucía aparentemente no afecta a las rocas sedimentarias y volcánicas cenozoicas de la región, mientras que el fallamiento frágil de Caltepec si las corta (Figura 12).

Las rocas sedimentarias y volcánicas que cubren al contacto tectónico entre los complejos Acatlán y Oaxaqueño fueron descritas con detalle en el área de Tamazulapan como Conglomerado Tamazulapan, Formación Yanhuitlán, Toba Llano de Lobos, Toba Cerro Verde, Andesita Yucudaac, Andesita San Marcos y Formación Chilapa (FerrusquíaVillafranca et al., 1974; Ferrusquía-Villafranca, 1976). La parte superior de la Toba Llano de Lobos y la base de la Andesita Yucudaac dieron edades K-Ar (biotita y roca entera) de $28.9 \pm 0.6 \mathrm{Ma}$ y de $26.2 \pm 0.5 \mathrm{Ma}$, respectivamente (Ferrusquía-Villafranca et al., 1974). Esta secuencia llega a tener hasta $1000 \mathrm{~m}$ de espesor y presenta varias discordancias que pueden estar registrando parte de la historia tectónica cenozoica de la falla de Caltepec. Así por ejemplo, la reactivación frágil de la falla de Caltepec en su prolongación al sur, en el área de Tlapiltepec-Tejuapan (Figura 12), corta a rocas piroclásticas, volcaniclásticas y volcánicas de la Toba Llano de Lobos y de la Andesita Yucudaac del Oligoceno, lo que evidencia actividad neogénica de la falla, con desplazamientos verticales y componente lateral importante asociados con plegamiento local de la cobertura volcaniclástica. Martiny et al. (2000) propusieron que la distribución regional de las rocas volcánicas oligocénicas del sur de México está controlada por fallas con desplazamiento lateral y oblicuo, que en conjunto definen un sistema escalonado de desplazamiento lateral izquierdo.

\subsection{Actividad tectónica reciente}

Actividad tectónica reciente puede estar ocurriendo a lo largo de la zona de falla de Caltepec, como lo sugiere la información sismológica disponible. De acuerdo con lo registrado solamente en los últimos 14 años por la red sismológica nacional, en la región de Tehuacán y centronorte del estado de Oaxaca han ocurrido cerca de un centenar de sismos con magnitudes de 3.4 a 7.0 e hipocentros con profundidades que varían desde $6 \mathrm{~km}$ hasta $178 \mathrm{~km}$ (Servicio Sismológico Nacional, comunicación escrita, 28/abril/2004). De todos estos sismos, sólo 21 pueden tener alguna relación con el sistema de fallas de Caltepec dada la ubicación de sus epicentros (Figura 12). Sin embargo, debido a que según la geometría de las placas Rivera y Cocos subducidas debajo de la placa de América de Norte en el sur de México (Pardo y Suárez, 1995), la profundidad de la zona de Wadati-Benioff varía de $\sim 50 \mathrm{Km}$ en el límite sur a $\sim 80 \mathrm{~km}$ en el límite norte de esta región de Nochixtlán-Tehuacán, y a que el espesor cortical es de 40-45 km de 


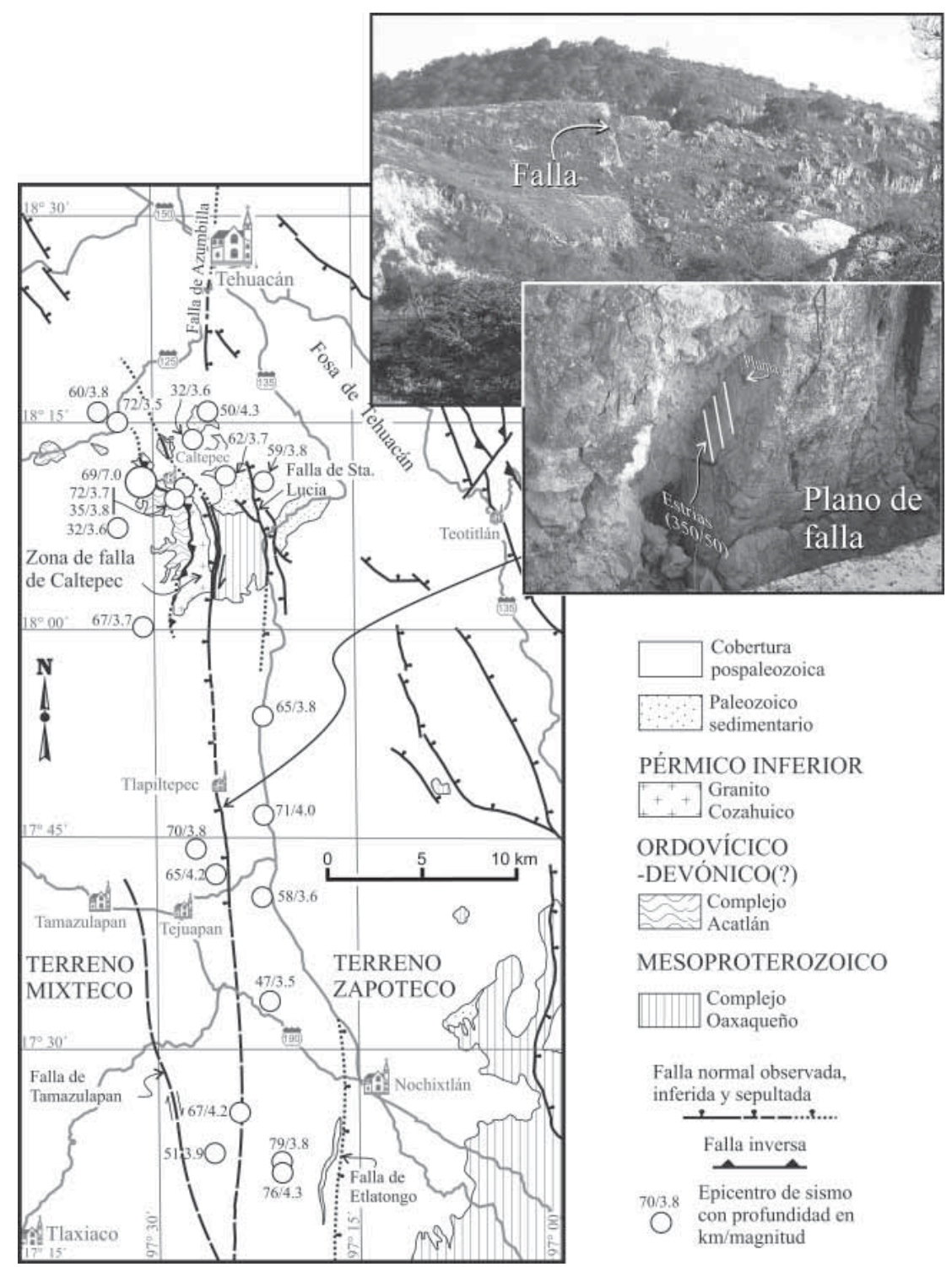

Figura 12. Reactivación frágil de la falla de Caltepec en su prolongación hacia el sur, en la región centro-norte del estado de Oaxaca. En el área de Tlapiltepec-Tejuapan, al NE de Tamazulapan, la falla está cortando a rocas piroclásticas, volcaniclásticas y volcánicas del Oligoceno. Los rasgos de la falla en el área sugieren un movimiento normal con el bloque caído al poniente y una componente lateral menor. Las estrías en el plano de falla tienen una inclinación de $50^{\circ}$ a $350^{\circ}$ (para escala se señala la pluma). La traza de la falla de Tamazulapan con movimiento lateral izquierdo es según LópezTicha (1985). Los sismos ocurridos en el período de 1990-2003 que pueden estar relacionados con actividad tectónica reciente de la falla de Caltepec son incluidos. La magnitud de la mayoría de estos sismos fue de 3.5 a 4.3 y la profundidad de los hipocentros varía desde $32 \mathrm{~km}$ hasta $79 \mathrm{~km}$, sólo uno fue de 7.0 con epicentro muy cerca del poblado de Caltepec (Servicio Sismológico Nacional, comunicación escrita, 28/abril/2004). Para la discusión de los sismos ver el texto.

acuerdo con anomalías gravimétricas (Urrutia-Fucugauchi y Flores-Ruiz, 1996; Campos-Enríquez y Sánchez-Zamora, 2000), el número de sismos que pueden tener una relación directa con el sistema de falla de Caltepec se reduce considerablemente. De acuerdo con esta estructura de corteza y a la profundidad de los hipocentros (Figura 12), varios de los sismos que se distribuyen a lo largo de la traza de la zona de falla de Caltepec ocurrieron consecuentemente en la placa oceánica subducida o en la zona de Wadati-Benioff, otros en la cuña de manto litosférico subcontinental, y sólo tres en la corteza media-inferior. El sismo mayor con magnitud 7 y epicentro cercano a Caltepec (Figura 12) dada su profundidad, probablemente está más bien relacionado al deslizamiento de la placa de Cocos en la zona WadatiBenioff, mientras que los sismos en el manto y la corteza, con magnitudes de 3.5-4.3, sugieren un comportamiento frágil que puede estar relacionado con la prolongación a profundidad de la zona de falla de Caltepec como estructura litosférica. En áreas con flujo de calor bajo, como podría ser el caso en la región de la zona de falla de Caltepec, se ha reportado ruptura sísmica no sólo en la corteza inferior sino también en el manto superior (e.g., Chen y Molnar, 
1983), lo cual es consistente con el hecho de que la prolongación hacia el norte de la falla de Caltepec coincida justamente con la porción de la Faja Volcánica Transmexicana más angosta y alejada de la trinchera mesoamericana. Actualmente, sin embargo, está claro que la sismotectónica que puede estar relacionada con la falla de Caltepec es un aspecto que debe ser abordado con más profundidad.

\section{Conclusiones}

De acuerdo con el estado actual del conocimiento sobre la falla de Caltepec discutido en este trabajo, y con el fin de dar mayor claridad a lo alcanzado hasta ahora, enseguida se enumeran las conclusiones fundamentales, considerando que un conocimiento pleno de esta estructura a lo largo de toda su historia tectónica es esencial para el entendimiento de la evolución geológica del sur de México.

1. La falla de Caltepec es una frontera geológica o estructura cortical de larga vida que representa el contacto tectónico indiscutible entre los complejos Oaxaqueño y Acatlán, basamentos cristalinos de los terrenos más importantes del sur de México: Zapoteco y Mixteco, respectivamente.

2. Debido a la antigüedad y relevancia regional de la falla, y a la calidad de sus afloramientos, el registro geológico de su actividad tectónica tan prolongada se puede estudiar con detalle excepcional desde un bloque al otro y a niveles de exposición mesocorticales para su parte dúctil y epicorticales para su parte frágil. La falla de Caltepec es también un laboratorio natural ideal para estudiar procesos de deformación dúctil y magmatismo sintectónico que operan al nivel de corteza media, y mecanismos de reactivación en zonas de falla mayores.

3. La actividad más antigua y profunda hasta ahora documentada en la zona de falla es un evento tectonomagmático-metamórfico caracterizado por migmatización, magmatismo sintectónico, y cizallamiento dúctil transpresional derecho, que fue fechado por métodos isotópicos $\mathrm{U}-\mathrm{Pb}$ en circones y cubre un intervalo entre $275.6 \pm 1 \mathrm{Ma}$ (leucosoma anatéctico) y $270 \pm 2.6 \mathrm{Ma}$ (granito Cozahuico). Este evento se relaciona con una colisión oblicua entre los bloques continentales Oaxaquia en su porción meridional (Complejo Oaxaqueño) y Acatlán. Durante el Pérmico temprano este evento formó parte de un frente colisional paleogeográficamente complejo entre Laurencia y Gondwana que concluyó con la consolidación de Pangea.

4. Por sus características petrográficas y estructurales, el granito Cozahuico, emplazado en la zona de falla, se considera un intrusivo sintectónico, producto de la fusión local de corteza proterozoica durante el fallamiento, pero con una contribución contemporánea importante de magmas subcorticales. Datos isotópicos de Rb-Sr y Sm-Nd son consistentes con la inferencia anterior.

5. El levantamiento de la zona de falla ocurrió a una tasa muy elevada sugerida por epidota magmática en el granito Cozahuico y en el leucosoma anatéctico, y una edad de enfriamiento ${ }^{40} \mathrm{Ar} /{ }^{39} \mathrm{Ar}$ de $268.6 \pm 1.27$ Ma de mica blanca en esquisto de mica milonitizado, muy similar a las edades de los de los circones del granito y del leucosoma, así como por la edad leonardiana de la Formación Matzitzi, unidad de traslape discordante más antigua.

6. La zona de falla de Caltepec, luego de su exposición en superficie hace unos $265 \mathrm{Ma}$, experimentó actividad tectónica intermitente durante el Mesozoico y Cenozoico, cuyas causas podrían relacionarse en buena medida en los movimientos tectónicos asociados con la dispersión de Pangea y la evolución del margen del Pacífico del sur de México. Reactivaciones neogénicas indicadas por relaciones de campo, y posiblemente también recientes como lo sugiere datos sismológicos con hipocentros profundos, vienen a corroborar que la falla de Caltepec es una discontinuidad cortical de larga vida.

\section{Agradecimientos}

Este trabajo fue desarrollado y financiado bajo el marco del proyecto SEP-CONACYT 36821-T. La revisión crítica del manuscrito fue hecha por Bodo Weber y Susana Alaniz, cuyas sugerencias y comentarios fueron muy constructivos para centrar nuestas ideas y mejorar el trabajo. Agradecemos a Edgar Angeles Moreno por la ayuda brindada en algunas etapas del trabajo de campo. Sonia Ángeles participó activamente en el proceso de separación de minerales para fechamientos. El Servicio Simológico Nacional dependiente del Instituto de Geofísica, de la UNAM, amablemente facilitó la información relacionada con los sismos localizados en la región de Tehuacán, Puebla, y porción central del estado de Oaxaca. A. Iriondo agradece al Dr. Joe Wooden del United States Geological Survey por su apoyo durante la realización de los fechamientos $\mathrm{U}-\mathrm{Pb}$ de circones con SHRIMP.

\section{Referencias bibliográficas}

Alaniz-Álvarez, S. A., van der Heyden, P., Nieto-Samaniego, A. F., Ortega-Gutiérrez, F., 1996, Radiometric and kinematic evidence for Middle Jurassic strike-slip faulting in southern Mexico related to the opening of the Gulf of Mexico: Geology, 24, 443-446.

Alzaga-Ruiz, H., 1991, Estratigrafía y consideraciones paleogeográficas de las rocas del Jurásico Tardío-Cretácico Temprano, en el área de Tomellín-Santiago Nacaltepec, Oaxaca, México: Revista del Instituto Mexicano del Petróleo, XXIII (2), 17-27.

Ángeles-Moreno, E., Elías-Herrera, M., Sánchez-Zavala, J. L., MacíasRomo, C., Ortega-Rivera, A., Iriondo, A., 2004, Terreno Cuicateco, sur de México: evolución tectónica de una cuenca pull-apart para 145-132 Ma: IV Reunión Nacional de Ciencias de la Tierra, Libro de Resúmenes, Centenario de la Sociedad Geológica Mexicana, 66-67.

Brown, M., Solar, G. S., 1998, Shear-zone systems and melts: Feedback relations and self-organization in orogenic belts: Journal of Structural Geology, 20, 211-227.

Bullard, E. C., Everett, J. E., Smith, A. G., 1965, The fit of continents around the Atlantic, en Blackett, P. M. S., Bullard, E. C., Runcorn, 
S. K., (eds.), A symposium on continental drift: Royal Society of London Philosophical Transactions, Serie A, Mathematical and Physical Sciences, 258, 41-51.

Calderón-García, A., 1956, Bosquejo geológico de la región de San Juan Raya, Pue., en XX Congreso Geológico Internacional, Estratigrafía del Mesozóico y tectónica del sur de Puebla; Presa de Valsequillo, Sifón de Huexotitlanapa y problemas hidrológicos de Puebla. Libro guía de la excursión A-11: México, El Congreso, 9-27.

Campos-Enríquez, J. O., Sánchez-Zamora, O., 2000, Crustal structure across southern Mexico inferred from gravity data: Journal of South American Earth Sciences, 13, 479-489.

Carpenter, D. L., 1997, Tectonic history of the metamorphic basement rocks of the Sierra del Carmen, Coahuila, Mexico: Geological Society of America Bulletin, 109, 1321-1332.

Chen, W. P., Molnar, P., 1983, Focal depths of intracontinental and intraplate earthquakes and their implications for the thermal and mechanical properties of the lithosphere: Journal of Geophysical Research, 88 (B5), 4183-4214.

Clark, A. H., Archibald, D. A., Lee, A. W., Farrar, E., Hodgson, C. J., 1998, Laser probe ${ }^{40} \mathrm{Ar} /{ }^{39} \mathrm{Ar}$ ages of early- and late-stage alteration assemblages, Rosario porphyry copper-molybdenum deposit, Collahuasi District, I Region, Chile: Economic Geology, 93, 326-337.

De Cserna, Zoltan, 1970, Reflexiones sobre algunos de los problemas de la geología de la parte centromeridional de México, en Segura, R. L., Torres-Rodríguez, R., (eds.), Libro-guía de la excursión MéxicoOaxaca, Sociedad Geológica Mexicana, 37-50.

DePaolo, D. J., 1981, Neodymium isotopes in the Colorado Front Range and crust-mantle evolution in the Proterozoic: Nature, 291, 193196.

Drummond, M. S., Neilson, M. J., Allison, D. T., Tull, J. F., 1997, Igneous petrogenesis and tectonic setting of granitic rocks from the eastern Blue Ridge and Inner Piedmont, Alabama Appalachians, en Sinha, A. K., Whalen, J. B., Hogan, J. P., (eds.), The Nature of Magmatism in the Appalachian orogen: Boulder, Geological Society of America Memoir, 191, 147-164.

Elías-Herrera, M., Ortega-Gutiérrez, F., 1998, The Caltepec fault zone, southern México: Devonian dextral shear interaction between the Precambrian Oaxacan and Paleozoic Acatlán basement complexes: en International Geological Correlation Program, Project No. 376, Laurentia-Gondwana connections before Pangea, Program and Abstracts: Oaxaca, Universidad Nacional Autónoma de México, Instituto de Geología, 15.

Elías-Herrera, M., Ortega-Gutiérrez, F., 2000, Roots of the Caltepec Fault Zone, southern México: Early Permian epidote-bearing anatexitic granitoids, en II Reunión Nacional de Ciencias de la Tierra, Resúmenes y Programas: Geos, 20 (3), 323.

Elías-Herrera, M., Ortega-Gutiérrez, F., 2002, The Caltepec fault zone: an Early Permian dextral transpressional boundary between the Proterozoic Oaxacan and Paleozoic Acatlán complexes, southern Mexico and regional tectonic implications: Tectonics, 21(3), 10.1029/2000TC001278, 4-1-4-19.

Ferrusquía-Villafranca, I., 1976, Estudios geológico-paleontológicos en la región Mixteca, Parte 1, Geología del área Tamazulapan, Teposcolula-Yanhuitlán, Mixteca Alta, Estado de Oaxaca: Univesidad Nacional Autónoma de México, Instituto de Geología, Boletín, 97, $160 \mathrm{p}$

Ferrusquía-Villafranca, I., Wilson, J. A., Denison R. E., Mc Dowell, F. W., Solorio-Munguia, J., 1974, Tres edades radiométricas oligocénicas y miocénicas de rocas volcánicas de las regiones de la Mixteca Alta y Valle de Oaxaca, Estado de Oaxaca: Boletín de la Asociación Mexicana de Geólogos Petroleros, 26, 249-262.

Gapais, D., 1989, Shear structure within deformed granites: Mechanical and thermal indicators: Geology, 17, 1144-1147.

García-Duarte, R., 1999, Evidencias de la naturaleza estructural y relaciones estratigráficas de la Formación Matzitzi en el sur de Puebla, México: Hermosillo, Sonora, Centro de Estudios Superiores del Estado de Sonora, Tesis profesional, 90 p.

González-Hervert, M. G., Martínez-González, P. R., Martínez-Graza, J. A., Rosas-Rojas, R., 1984, Características estratigráficas y estructurales del límite de los terrenos Mixteco y Oaxaca, en la región de Los Reyes Metzontla, Puebla: Boletín de la Sociedad Geológica Mexicana, 45, 21-32.

González-Ramos, A., Sánchez-Rojas, L. E., Mota-Mota, S., Arceo y Cabrilla, F. A., Soto-Araiza, R., Onofre-Espinosa, L., Zárate-López, J., 2000. Carta Geológico-Minera Oaxaca E14-9, escala 1:250,000: Pachuca, Hidalgo, Secretaría de Comercio y Fomento Industrial, Consejo de Recursos Minerales, 1 mapa.

Gradstein, F. M., Ogg, J. G., Smith, A. G., Bleeker, W., Lourens, L. J., 2004, A new Geologic Time Scale with special reference to Precambrian and Neogene: Episodes, 27 (2), 83-100.

Grajales-Nishimura, J. M., 1988, Geology, geochronology, geochemistry, and tectonic implications of the Juchatengo green rocks sequence, state of Oaxaca, southern Mexico: Tucson, University of Arizona, Tesis de maestría, $145 \mathrm{p}$.

Grajales-Nishimura, J. M., Torres-Vargas, R., Murillo-Muñetón, G., 1986, Datos isotópicos K-Ar para rocas ígneas y metamórficas en el estado de Oaxaca, en VIII Convención Geológica Nacional, Libro de Resúmenes: México, Sociedad Geológica Mexicana, 150-151.

Grajales-Nishimura, J. M., Centeno-García, E., Keppie, J. D., Dostal, J., 1999, Geochemistry of Paleozoic basalt from the Juchatengo complex of southern Mexico: tectonic implications: Journal of South America Earth Sciences, 12, 537-544.

Hames, W. E., Bowring, S. A., 1994, An empirical evaluation of the argon diffusion geometry in muscovite: Earth and Planetary Science Letters, 124, 161-167.

Harrison, T. M., 1981, Diffusion of ${ }^{40} \mathrm{Ar}$ in hornblende: Contribution to Mineralogy and Petrology, 78, 324-331.

Harrison, T. M., Grove, M., Lovera, O. M., Catlos, E. J., 1998, A model for the origin of Himalayan anatexis and inverted metamorphism: Journal of Geophysical Research, 103 (B11), 22017-27032.

Hernández-Lascares, D., 2000, Contribución al conocimiento de la estratigrafía de la Formación Matzitzi, área Los Reyes MetzontlaSantiago Coatepec, extremo suroriental del estado de Puebla: México, Universidad Nacional Autónoma de México, Colegio de Ciencias y Humanidades, Unidad Académica de los Ciclos Profesionales y De Posgrado, Tesis de maestría, $117 \mathrm{p}$.

Hernández-Estevez, S., 1980, Libro-guía de la excursión geológica al borde noroeste de la paleopeninsula de Oaxaca (sureste del Estado de Puebla): México, Sociedad Geológica Mexicana, $11 \mathrm{p}$.

Holdsworth, R. E., Butler, C. A., Roberts, A. M., 1997, The recognition of reactivation during continental deformation: Journal of the Geological Society, London, 154, 73-78.

Holdsworth, R. E., Hand, M., Miller, J. A., Buick, I. S., 2001a, Continental reactivation and reworking: an introduction en Miller, J. A., Holdsworth, R. E., Buick, I. S., Hand, M., (eds.), Continental reactivation and reworking: London, Geological Society, Special Publication, 184, 1-12.

Holdsworth, R. E., Stewart, M., Imber, J., Strachan, R. A., I., 2001b, The strucuture and rheological evolution of reactivated continental fault zones: a review and case study en Miller, J. A. Holdsworth, R. E. Buick, I. S. Hand, M. (eds.), Continental Reactivation and Reworking: London, Geological Society, Special Publication, 184, 115-137.

Keane, S. D., Morrison, J., 1997, Distinguishing magmatic from subsolidus epidote: laser probe oxygen isotope compositions: Contribution to Mineralogy and Petrology, 126, 265-274.

Keppie, J. D., Dostal, J. Cameron, K. L., Solari, L. A, Ortega-Gutiérrez, F., López, R., 2003, Geochronology and geochemistry of Grenvillian igneous suites in the northern Oaxacan Complex, southern Mexicotectonic implications: Precambrian Research, 120, 365-389.

Krogh, T. E., 1973, A low contamination method for hydrothermal decomposition of zircon and extraction of $\mathrm{U}$ and $\mathrm{Pb}$ for isotopic age determination: Geochimica. et Cosmochimica. Acta, 37, 485494.

Leloup, P. H., Ricard, Y. Battaglia, J., Lacassin, R., 1999, Shear heating in continental strike-slip shear zones: model and field examples: Geophysical Journal International, 136, 19-40.

López, R., 1997, High-Mg andesites from the Gila Band Mountains, southwestern Arizona: evidence for hydrous melting of lithosphere 
during Miocene extension; the pre-Jurassic geotectonic evolution of the Coahuila terrane, northwestern Mexico: Grenville basement, a late Paleozoic arc, Triassic plutonism, and the events south of the Ouachita suture: Santa Cruz, California, University of California, Tesis de doctorado, $147 \mathrm{p}$.

López-Ticha, D., 1985, Revisión de la estratigrafía y potencial petrolero de la cuenca de Tlaxiaco: Boletín de la Asociación Mexicana de Geólogos Petroleros, 37, 49-92.

Ludwig, K. R., 1991, PBDAT; forms-DOS, a computer programs for IBM-PC compatibles for processing raw for processing $\mathrm{Pb}-\mathrm{U}-\mathrm{Th}$ isotope data, version 1.20: Washington, D. C., U. S. Geological Survey, Open File Report, 88-542, 37 p.

Ludwig, K. R., 2001a, ISOPLOT/Ex, version 2.49, A geocronological toolkit for microsoft excel: Berkeley, California, Berkeley Geochronology Center, Special Publication 1, 56 p.

Ludwig, K. R., 2001b, SQUID, version 1.00, A user's manual: Berkeley, California, Berkeley, Geochronology Center, Special Publication 2, $17 \mathrm{p}$.

Martiny, B., Martínez-Serrano, R. G., Morán-Zenteno, D., J., MacíasRomo, C., Ayuso, R. A., 2000, Stratigraphy, geochemistry and tectonic significance of the Oligocene magmatic rocks of western Oaxaca, southern México: Tectonophysics, 318, 71-98.

Mattinson, J. M., 1987, U-Pb ages of zircons: a basic examination of error propagation: Chemical Geology (Isotope Geoscience Section), 66, 151-162.

Mawer C. K., Rubie, D. C., Bearley, A. J., 1988, A model for rapid melting in crustal shear zones: Eos, Transactions, American Geophysical Union, 69, 1411.

McDougall, I., and Harrison, T. M., 1988, Geochronology and Thermochronology by the ${ }^{40} \mathrm{Ar} /{ }^{39} \mathrm{Ar}$ method: Oxford, Oxford University Press, Oxford Monographs on Geology and Geophysics 9, $212 \mathrm{p}$.

Meneses-Rocha, J. J., Monroy-Audelo, M. E., Gómez-Chavarría, J. C., 1994, Bosquejo paleogeográfico y tectónico del sur de México durante el Mesozoico: Boletín de la Asociación Mexicana de Geólogos Petroleros, 44, 18-45.

Milisenda, C. C., Liew, T. C., Hofmann, A. W., Kohler, H., 1994, Nd isotopic mapping of the Sri Lanka basemente: update, and additional constrains from Sr isotopes: Precambrian Research, 66, 95-110.

Miller, R. B., Paterson, S. R., 1994, The transition from magmatic to high-temperature solid-state deformation: implications from the Mount Stuart batholith, Washington: Journal of Structural Geology, $16,853-865$.

Murillo-Muñetón, G., Grajales-Nishimura, J. M., Torres-Vargas, R., 1986, Estudio petrográfico y radiométrico por K-Ar de la porción centro sur del estado de Oaxaca, en VIII Conveción Geológica Nacional Resúmenes: Sociedad Geológica Mexicana, 149-150.

Nabelek, P. I., Liu, M., 1999, Leucogranites in the Black Hills of South Dakota: The consequence of shear heating during continental collision: Geology, 27, 523-526.

Ordóñez, E., 1905, Las rocas arcaicas de México: Memoria y Revista de la Sociedad Científica “Antonio Alzate” (México), 22, 315-331.

Ordóñez, E., 1906, L'Archaique du Cañon de Tomellin, en X Congress Geologique Internationale, Guide d'excursion: México, E1 Congreso 5, $30 \mathrm{p}$.

Ortega-Gutiérrez, F., 1975, The pre-Mesozoic geology of the Acatlán area, south Mexico: Leeds, University of Leeds, Tesis de doctorado $166 \mathrm{p}$.

Ortega-Gutiérrez, F., 1978, Geología del contacto entre la formación Acatlán paleozoica y el complejo Oaxaqueño precámbrico, al oriente de Acatlán, estado de Puebla: Boletín de la Sociedad Geológica Mexicana, 39, 27-28.

Ortega-Gutiérrez, F., 1981, Metamorphic belts of southern Mexico and their tectonic significance: Geofísica Internacional, 20, 177-202.

Ortega-Gutiérrez, F., 1993, Tectonostratigraphic análisis and significance of the Paleozoic Acatlán Complex of southern Mexico, in Ortega-Gutiérrez, F., Centeno-García, E., Morán-Zenteno, D.J., Gómez-Caballero, A., (eds.), First Circum-Pacific and CircumAtlantic Terrane Conference. Terrane geology of southern Mexico: Guidebook of field trip B: Guanajuato, Univesidad Nacional
Autónoma de México, Instituto de Geología, 54-60.

Ortega-Gutiérrez, F., Ruiz, J., Centeno-García, E., 1995, Oaxaquia, a Proterozoic microcontinent accreted to North America during the late Paleozoic: Geology, 23, 1127-1130.

Ortega-Gutiérrez, F., Elías-Herrera, M., Reyes-Salas, M., Macías-Romo, C., López R., 1999, Late Ordovician-Early Silurian continental collisional orogeny in southern Mexico and its bearing on Gondwana-Laurentia connections: Geology, 27, 719-722.

Pardo, M., and Suárez, G., 1995, Shape of the subducted Rivera and Cocos plates in southern Mexico: seismic and tectonic implications: Journal of Geophysical Research, 100 (B7), 12,357-12,373.

Parrish, R. R., 1987, An improved micro-capsule for zircon dissolution in U-Pb geochronology: Chemical Geology (Isotope Geoscience Section), 66, 99-102.

Paterson, S. R., Tobisch, O. T., 1988, Using pluton ages to date regional deformation: Problems with commonly used criteria: Geology, $16,1108-1111$.

Paterson, S. R., Vernon, R. H., and Tobish, O. T., 1989, A review of criteria for the identification of magmatic and tectonic foliations in granitoids: Journal of Structural Geology, 11, 349-363.

Paterson, S. R. Schmidt K. L., 1999, Is there a close relationship between faults and plutons?: Journal of Structural Geology, 21, $1131-1142$.

Ramírez-Espinosa, J., 1984, La acreción de los terrenos Mixteco y Oaxaca durante el Cretácico Inferior, Sierra Madre del Sur de México: Boletín de la Sociedad Geológica Mexicana, 45, 7-19.

Román-Bardiel, T., Gapais, D., Brun, J-P., 1997, Granite intrusion along strike-slip zones in experiment and nature: American Journal of Science, 297, 651-678.

Ross, C. A., 1986, Paleozoic evolution of southern margin of Permian basin: Geological Society of America Bulletin, 97, 536.554.

Ruiz-Castellanos, M., 1979, Rubidium-strontium geochronology of the Oaxaca and Acatlán metamorphic areas of southern Mexico: Dallas, University of Texas at Dallas, Tesis de doctorado $188 \mathrm{p}$.

Ruiz, J., Patchett, P. J., Ortega-Gutierrez, F., 1988a, Proterozoic and Phanerozoic basement terranes of México from Nd isotopic studies: Geological Society of America Bulletin, 100, 274- 281.

Ruiz, J., Patchett, P. J., Arculus, R. J., 1988b, Nd-Sr isotope composition of lower crustal xenoliths - Evidence for the origin of mid-tertiary felsic volcanics in Mexico: Contribution to Mineralogy and Petrology, 99, 36-43.

Saint Blanquat, M., Tikoff, B., Teyssier, C., Vigneresse, J. L., 1998, Transpressional kinematics and magmatic arcs, en Holdsworth, $\mathrm{R}$. E., Strachan, R. A., Dewey, J. E., (eds.), Continental Transpressional and Transtensional Tectonics: London, Geological Society, Special Publication, 135, 327-340.

Sampson, S. D., Coler, D. G., Speer, J. A., 1995, Geochemical and Nd$\mathrm{Sr}-\mathrm{Pb}$ isotopic composition of Alleghanian granites of the southern Appalachians: origin, tectonic setting, and source characterization: Earth and Planetary Science Letters, 134, 359-376.

Schmidt, M. W., Thompson, A. B., 1996, Epidote in calc-alkaline magmas: An experimental study of stability, phase relationships, and the role of epidote in magmatic evolution: American Mineralogist, $81,462-474$.

Sedlock, R. L., Ortega-Gutiérrez, F., Speed, R. C., 1993, Tectonostratigraphic terranes and tectonic evolution of Mexico: Boulder, Geological Society of America Special Paper, 278, 153 p.

Silva-Pineda, A., 1970, Plantas del Pensilvánico de la región de Tehuacán, Puebla: Universidad Nacional Autónoma. de México, Instituto de Geología, Paleontología Mexicana, 29, 47 p.

Solari, L. A, Keppie, J. D., Ortega-Gutiérrez, F., Cameron, K. L., Lopez, R., Hames, W. E., 2003, 990 Ma and 1,100 Ma grenvillian tectonothermal events in the northern Oaxacan Complex, southern México: Tectonophysics, 365, 257-282.

Stacey, J. S., Kramer J. D., 1975, Approximation of terrestrial lead isotope evolution by a two-stage model: Earth and Planetary Science Letters, 26, 207-221.

Torres-Torres, G., Ortega-González, J.V., Gutiérrez-Galicia, L., GarduñoMonroy, V.H., 1984, Estudio microestructural del límite oriental del terreno Mixteco entre Huajuapan de León y Teposcolula, Oaxaca: 
Boletín de la Sociedad Geológica Mexicana, 45, 39-41.

Torres-Vargas, R., Murillo-Muñeton, G., Grajales-Nishimura, M., 1986, Estudio petrográfico y radiométrico de la porción límite entre los complejos Acatlán y Oaxaqueño, en VIII Convención Geológica Nacional, Resúmenes: México, Sociedad Geológica Mexicana, 148-149.

Torres-Vargas., R., Ruiz, J., Patchett, P. J., Grajales, J. M., 1999, PermoTriassic continental arc in eastern Mexico: tectonic implications for reconstructions of southern North America, en Bartolini, C. Wilson, J. L., Lawton T. F., (eds.), Mesozoic Sedimentary and Tectonic History of North-Central Mexico: Boulder, Geological Society of America Special Paper 340, 191-196.

Urrutia-Fucugauchi, J., Flores-Ruiz, J. H., 1996, Bouguer gravity anomalies and regional crustal structure in central Mexico: International Geology Review, 38, 176-194.

Vega-Carrillo, J. J., Elías-Herrera, M., Ortega-Gutiérrez, F., 1998, Complejo plutónico de Cuanana: basamento prejurásico en el borde meridional del terreno Mixteco e interpretación litotectónica, en Alaniz-Álvarez, S. A., Ferrari, L., Nieto-Samaniego, Á. F., OrtegaRivera, M. A., (eds.), Libro de resúmenes: México, Sociedad Geológica Mexicana; Instituto Nacional de Geoquímica; Sociedad Mexicana de Geomorfología; Sociedad Mexicana de Mineralogía; Asociación Mexicana de Geólogos Petroleros, Primera Reunión Nacional de Ciencias de la Tierra, 145.

Vigneresse, J. L., 1995, Control of granite emplacement by regional deformation: Tectonophysics, 249, 173-186.

Wijbrans, J. R., McDougall, I., 1986, ${ }^{40} \mathrm{Ar} /{ }^{39} \mathrm{Ar}$ dating of white micas from an Alpine high-pressure metamorphic belt on Naxos (Greece): the resetting of the argon isotopic system: Contributions to Mineralogy and Petrology, 93, 187-194.

Weber, R., 1997, How old is the Triassic flora of Sonora and Tamaulipas and news on Leonardian flora in Puebla and Hidalgo, Mexico: Revista Mexicana de Ciencias Geológicas, 14, 225-243.
Weber, R., Centeno-García, E., y Magallón-Puebla, S. A., 1987, La Formación Matzitzi, estado de Puebla, tiene una edad permocarbonífera, en Segundo Simposio sobre la Geología Regional de México, Programa y Resúmenes: México, Universidad Nacional Autónoma de México, Instituto de Geología, 57-59.

Weber, B., Kohler, H., 1999, Sm-Nd, Rb-Sr and U-Pb geochronology of a Grenville terrane in southern Mexico: origin and geologic history of the Guichicovi Complex: Precambrian Research, 96, 245-262.

Williams, I. S., 1998, U-Th-Pb geochronology by ion microprobe, en McKibben M. A., Shanks W. C., Ridley, W. I., (eds.), Applications of microanalytical techniques to understanding mineralization processes, Reviews in Economic Geology, 7, 1-35.

Yañez, P., Ruiz, J., Patchett, P. J., Ortega-Gutiérrez, F., Gehrels, G. E., 1991, Isotopic studies of the Acatlán Complex, southern Mexico: implications for Paleozoic North American tectonics: Geological Society of America Bulletin, 103, 817-828.

Zen, E-A., Hammarstrom, J. M., 1984, Magmatic epidote and its petrologic significance: Geology, 12, 515-518.

Zeng, L., Saleeby, J., B., Asimov, P., 2005, Nd isotope disequilibrium during crustal anatexis: A record from the Goatt Ranch migmatite complex, soutthern Sierra Nevada batholith, California: Geology, 33, 53-56.

Manuscrito recibido: Agosto 12, 2004

Manuscrito corregido recibido: Febrero 03, 2005

Manuscrito aceptado: Febrero 11, 2005 